PARKTEAVIS

\section{田 NEURONTN}

(Gabapentin)

$100 \mathrm{mg}, 300 \mathrm{mg}, 400 \mathrm{mg}$ Copsules

Antiepiteptic Agent

\section{ACTION AND CUNICAL PHARMACOLOGY}

Gabapentin exhibits antiseizure activity in mice and rats both in the maximal electroshock and in the pentylenetetrazol seizure models.

Gabapentin is structurally related to the neurotransmitter GABA lgamma-aminobutyric acid) but does not interact with GABA receptors, it is not metobolized to GABA or to GABA agonists, and it is not an inhibitor of GABA uptake or degradation. Gabapentin at concentrations up to $100 \mu \mathrm{M}$ did not demonstrate affinity for other receptor sites such as benzodiazepine, glutamate, glycine or $\mathrm{N}$-methyl-D-aspartate receptors nor does it interact with neuronol sodium channels or L-type calcium channels.

The mechanism of action of gabapentin has not yet been established, however, it is unlike that of the commonly used anticonvulsant drugs.

In vitro studies with radiolabelled gabapentin have revealed a gabapentin binding site in rat brain tissues including neocortex and hippocompus. The identity and function of this binding site remain to be elucidated.

\section{Pharmacokinetics}

\section{Adults:}

Following oral administration of Neurontin (gabapentin), peak plasma concentrations ore observed within 2 to 3 hours. Absolute bioovailability of a $300 \mathrm{mg}$ dose of Neurontin capsules is approximately $59 \%$. At doses of 300 and $400 \mathrm{mg}$, gabapentin bioavailability is unchanged following multiple dose administration. Gabapentin elimination from plasma is best described by linear pharmocokinetics. The elimination half-life of gabapentin is independent of dose and averoges 5 to 7 hours in subjects with normal renal function.

Plasma gabapentin concentrations are dose-propartional at doses of 300 to $400 \mathrm{mg} \mathrm{q} 8 \mathrm{~h}$, ranging between $1 \mu \mathrm{g} / \mathrm{mL}$ and $10 \mu \mathrm{g} / \mathrm{mL}$, but are less than dose-proportional above the elinical range $1>600 \mathrm{mg}$ $\mathrm{q} 8 \mathrm{~h})$. There is no correlation between plasma levels and efficacy. Gabapentin pharmacokinetics are not affected by repeated administration, and steady stote plasma concentrations are predictable from single dose dato.

Gabapentin is not appreciably metabolized in humans, is eliminated solely by renal excretion, and can be removed from plasma by hemodialysis.

Gobopentin does not induce or inhibit hepatic mixed function oxidase enzymes responsible for drug metabolism, does not interfere with the metabolism of commonly coadministered antiepileptic drugs, and is minimally bound to plasma proteins.

Food has no effect on the rate or extent of absorption of gabapentin.

Table 1 summarizes the mean steady-state pharmacokinetic parameters of Neurontin capsules.

Toble 1: Summory of Neurontin (gabopentin) Meon Steody-State Pharmacokinetic Parameters in Adults Following Q8H Administration

\begin{tabular}{|l|c|c|}
\hline $\begin{array}{c}\text { Pharmacokinetic } \\
\text { Parameter }\end{array}$ & $\begin{array}{c}\mathbf{3 0 0} \mathbf{m g} \\
\mathbf{N = 7}\end{array}$ & $\begin{array}{c}\mathbf{4 0 0} \mathbf{~ m g} \\
\mathbf{N = 1 1}\end{array}$ \\
\hline $\mathrm{C}_{\max (\mu \mathrm{g} / \mathrm{mL})}$ & 4.02 & 5.50 \\
${ }^{\dagger} \max (\mathrm{hr})$ & 2.7 & 2.1 \\
$+1 / 2(\mathrm{hr})$ & 5.2 & 6.1 \\
$\mathrm{AUC}(\mathrm{o}-\propto)(\mu \mathrm{g} \bullet \mathrm{hr} / \mathrm{mL})$ & 24.8 & 33.3 \\
$\mathrm{AE} \%{ }^{1}$ & $\mathrm{NA}$ & 63.6 \\
\hline
\end{tabular}

Amount excreted in urine ( $\%$ of dose)

NA a Not ovailable

In patients with epilepsy, gabapentin concentrations in cerebrospinal fluid are approximately $20 \%$ of corresponding steady-state trough plasma concentrations.

Elderty:

Apparent oral clearance (CL/F) of gabapentin decrecsed as age increased, from about $225 \mathrm{~mL} / \mathrm{min}$ in subjects under 30 years of age to about $125 \mathrm{~mL} / \mathrm{min}$ in subjects over 70 years of age. Renal clearance $(\mathrm{CL}$ ) of gabapentin also declined with age; however, this decrease can largely be explained by the decline in renal function. Reduction of gabapentin dose may be required in patients who hove age-related compromised renal function (See Dosage and Administration).

\section{Renal Impaiment:}

In patients with impoired renal function, gabopentin clearance is markedly reduced and dosage odjustment is necessary (See Table 5 in Dosage and Administration!

\section{Hemodialysis:}

In a study in anuric subjects ( $N=11$ ) the apparent elimination halflife of gabapentin on non-dialysis days was about 132 hours; dialysis three times a week ( 4 hours duration) lowered the apparent half-life of gabapentin by about $60 \%$, from 132 hours to 51 hours. Hemodiatysis thus has a significant effect on gabapentin elimination in onuric subjects.

Dosage adjustment in patients undergoing hemodialysis is necessary (Se Table 5 in Dosage and Administration).

\section{Pediatric:}

There are no pharmacokinetic data available in children under 18 years of age.

\section{Hepatic Impaiment}

Becouse gabapentin is not appreciably metabolized in humans, no study wos performed in patients with hepatic impairment.

\section{Clinical Trials}

In placebo-controlled trials in patients not satisfactorily controlled with current antiepileptic drugs, Neurontin (gabapentin), when added to current antiepileptic therapy, was superior to placebo in reducing the frequency of both simple and complex partial seizures and secondarily generalized tonic-clonic seizures. Further analysis of data indicated a higher efficacy for complex partial seizures and secondarily generalized tonic-clonic seizures as compared to all seizure types. Doses ranged from 900 to $1800 \mathrm{mg} /$ day, with a median dose of $1200 \mathrm{mg} / \mathrm{doy}$.

Long-term, open, uncontrolled studies in drug-resistant patients for periods of up to 18 months demonstrated that doses up to $2400 \mathrm{mg} /$ day did not result in anything unusal in the type or frequency of adverse events.

\section{INDICATIONS AND CUNICAL USE}

Neurontin (gabapentin) is indicaled as adjunctive theropy for the management of patients with epilepsy who are not satisfactorily controlled by conventional therapy

\section{CONIRAINDICATIONS}

Neurontin (gabapentin) is contraindicated in patients who have demonstrated hypersensitivity to the drug or to any of the components of the formulation.

\section{PRECAUTIONS}

General

Neurontin (gabopentin) is not considered effective in the treatmen of absence seizures and should therefore be used with caution in patients who have mixed seizure disorders that include absence seizures.

\section{Tumorigenic Potential}

Gabapentin produced an increased incidence of acinar cel adenomas and carcinomas in the panereas of male rats, but not female rats or in mice, in oncogenic studies with doses of $2000 \mathrm{mg} / \mathrm{kg}$ which resulted in plasma concentrations 14 times higher than those occurring in humans at the maximum recommended dose of $2400 \mathrm{mg} /$ day. The relevance of these pancreatic acinar cell tumours in male rats to humans is unknown, particularly since tumours of duetal rather than acinar cell origin are the predominant form of human pancreatic cancer.

\section{Drug Discontinuation}

As with other anticonvulsant agents, abrupt withdrawal is not recommended because of the possibility of increased seizure frequency. When in the iudgement of the clinicion there is a need for dose reduction, discontinuation or substitution with alternative medication, this should be done gradually over a minimum of one week.

\section{Occupational Hazards}

Patients with uncontrolled epilepsy should not drive or handle potentially dangerous machinery. During clinical trials, the most common adverse reactions observed were somnolence, atoxia, fatigue and nystagmus. Patients should be advised to refrain from octivities requiring mental alertness or physical coordination until they are sure that Neurontin does not affect them adversely.

\section{Drug Interactions}

Antiepileptic Agents:

There is no interaction between Neurontin and phenytoin valproic acid, carbamazepine, or phenobarbital. Consequenty, Neurontin moy be used in combination with other commonly used ontiepileptic drugs without concerm for alteration of the plasme concentrations of gabapentin or the other antiepileptic drugs.

Gabapentin steady-state pharmacokinetics are similar for healthy subjects and patients with epilepsy receiving antiepileptic agents.

\section{Oral Contraceptives:}

Coadministration of Neurentin with the oral contraceptive NorlEstrin * does not influence the steady-state pharmocokinetics of norethindrone or ethinyl estrodiol.

Antocids:

Coadministration of Neurantin with an aluminum and magnesium based antacid reduces gabapentin bioavailability by up to $24 \%$ Although the clinical significance of this decrease is not known, coadministration of similar antacids and gabapentin is not recommended.

Probenecid:

Renal excretion of gabapentin is uncliered by probenecid.

Cimetidine:

A slight decrease in renal excretion of gabapentin observed when it is coadministered with cimetidine is not expected to be of clinical importance.

\section{Use in Pregnancy}

No evidence of impaired fertility or harm to the fetus due to gabopentin odministration was revealed in reproduction studies in mice at doses up to 62 times, and in rats ond rabbits at doses up to 31 times the human dose of $2400 \mathrm{mg} /$ day

There are, however, no adequate and well-controlled studies in pregnant women. Because animal reproduction studies are not always predictive of human response, this drug should only be used during pregnancy if the potential benefit to the mother justifies the potential risk to the fetus.

\section{Use in Lactotion}

It is not known if gabopentin is excreted in human milk, and the effect on the nursing infant is unknown. However, becouse many drugs are excreted in human milk, and because of the potential for serious adverse reactions in nursing infants from gabopentin, breast-feeding is only recommended if the potential benefit outweighs the potential risks.

\section{Use in Children}

Systematic studies to establish safety and efficacy in children hove not been performed. Dato in 39 patients between the ages of 12 and 18 yeors included in the double-blind, placebo-controlled trials showed that gabopentin wos superior to placebo in reducing seizure frequency. Safety data showed that the incidence of adverse events in this group of patients were similar to those observed in older individuals.

\section{Use in the Elderty}

Systematic studies in geriatric patients have not been conducted. Adverse clinical events reported among 59 patients over the age of 65 years trected with Neurontin did not differ from those reported for younger individuals. The small number of individuals evaluated and the limited duration of exposure limits the strength of any conclusions reached about the influence of age, if any, on the kind and incidence of adverse events associoted with the use of Neurontin.

As Neurontin is eliminated primarily by renal exeretion, dosage adjustment may be required in elderty patients because of declining renal function (See Dosage and Administration)

\section{Use in Renal Impoirment}

Gabapentin eleorance is markedly reduced in this patient population and dosage reduction is necessary (See Table 5 in Dosage and Administration).

\section{Loboratory Tests}

Clinical trials data do not indicate that routine monitoring of elinical laboratory parameters is necessary for the safe use of Neurontin. Neurontin may be used in combination with other commonly used antiepileptic drugs without concern for alteration of the blood concentrations of gabapentin or other antiepilepric drugs.

for urinary protein determination the sulfosalicylic acid precipitation procedure is recommended, as false positive readings were reported with the Ames $\mathrm{N}$-Multistix $\mathrm{SG}^{\circ}$ dipstick test, when gabapentin or placebo was added to other onticonvulsant drugs. 


\section{ADVERSE REACTIONS}

\section{Incidence in Controlled Clinical Trials}

Table 2 lists treatment-emergent signs and symptoms that occurred in at least $1 \%$ of patients with partial seizures participating in placebo-controlled studies. In these studies, either Neurontin (at doses of $600,900,1200$ or $1800 \mathrm{mg} /$ day) or placebo were added to the patient's current antiepileptic drug therapy.

The most commonly observed adverse events associated with the use of Neurontin in combination with other antiepileptic drugs, not seen at an equivalent frequency in placebo-treated patients, were somnolence, dizziness, ataxia, fatigue, nystagmus and tremor.

Among the treatment-emergent adverse events occurring in Neurontin-treated patients, somnolence and ataxia appeared to exhibit a positive dose-response relationship. Patients treated with $1800 \mathrm{mg} /$ day ( $\mathrm{n}=54$, from one controlled study) experienced approximately a two-fold increase, as compared to patients on lower doses of 600 to $1200 \mathrm{mg} /$ day $(\mathrm{n}=489$, from several controlled studies), in the incidence of nystagmus $(20.4 \%)$, tremor $(14.8 \%)$, rhinitis (13\%), peripheral edema (7.4\%), abnormal coordination, depression and myalgia (all at 5.6\%). Adverse events were usually mild to moderate in intensity, with a median time to resolution of 2 weeks.

Since Neurontin was administered most often in combination with other antiepileptic agents, it was not possible to determine which agent(s) was associated with adverse events.

Table 2: Treatment-Emergent Adverse Event Incidence in Placebo Controlled Add-On Trials (Events in at Least 1\% of Neurontin Patients and Numerically More Frequent than in the Placebo Group)

\begin{tabular}{|c|c|c|}
\hline $\begin{array}{l}\text { BODY SYSTEM/ } \\
\text { ADVERSE EVENT (AE) }\end{array}$ & $\begin{array}{c}\text { Neurontin } \\
\mathrm{N}=543 \\
\%\end{array}$ & $\begin{array}{c}\text { Placebo }^{\circ} \\
N=378 \\
\%\end{array}$ \\
\hline $\begin{array}{l}\text { BODY AS A WHOLE: } \\
\text { Fatigue } \\
\text { Weight Increase } \\
\text { Back Pain } \\
\text { Peripheral Edema }\end{array}$ & $\begin{array}{r}11.0 \\
2.9 \\
1.8 \\
1.7\end{array}$ & $\begin{array}{l}5.0 \\
1.6 \\
0.5 \\
0.5\end{array}$ \\
\hline $\begin{array}{l}\text { CARDIOVASCULAR: } \\
\text { Vasodilatation }\end{array}$ & 1.1 & 0.3 \\
\hline $\begin{array}{l}\text { DIGESTIVE SYSTEM: } \\
\text { Dyspepsia } \\
\text { Dry Mouth or Throat } \\
\text { Constipation } \\
\text { Dental Abnormalities } \\
\text { Increased Appetite }\end{array}$ & $\begin{array}{l}2.2 \\
1.7 \\
1.5 \\
1.5 \\
1.1\end{array}$ & $\begin{array}{l}0.5 \\
0.5 \\
0.8 \\
0.3 \\
0.8\end{array}$ \\
\hline $\begin{array}{l}\text { HEMATOLOGIC AND } \\
\text { LYMPHATIC SYSTEMS: } \\
\text { Leukopenia }\end{array}$ & 1.1 & 0.5 \\
\hline $\begin{array}{l}\text { MUSCULOSKELETAL SYSTEM: } \\
\text { Myalgia } \\
\text { Fracture }\end{array}$ & $\begin{array}{l}2.0 \\
1.1\end{array}$ & $\begin{array}{l}1.9 \\
0.8\end{array}$ \\
\hline $\begin{array}{l}\text { NERVOUS SYSTEM: } \\
\text { Somnolence } \\
\text { Dizziness } \\
\text { Ataxia } \\
\text { Nystagmus } \\
\text { Tremor } \\
\text { Nervousness } \\
\text { Dysarthria } \\
\text { Amnesia } \\
\text { Depression } \\
\text { Abnormal Thinking } \\
\text { Twitching } \\
\text { Abnormal Coordination }\end{array}$ & $\begin{array}{r}19.3 \\
17.1 \\
12.5 \\
8.3 \\
6.8 \\
2.4 \\
2.4 \\
2.2 \\
1.8 \\
1.7 \\
1.3 \\
1.1\end{array}$ & $\begin{array}{l}8.7 \\
6.9 \\
5.6 \\
4.0 \\
3.2 \\
1.9 \\
0.5 \\
0.0 \\
1.8 \\
1.3 \\
0.5 \\
0.3\end{array}$ \\
\hline $\begin{array}{l}\text { RESPIRATORY SYSTEM: } \\
\text { Rhinitis } \\
\text { Pharyngitis } \\
\text { Coughing }\end{array}$ & $\begin{array}{l}4.1 \\
2.8 \\
1.8\end{array}$ & $\begin{array}{l}3.7 \\
1.6 \\
1.3\end{array}$ \\
\hline $\begin{array}{l}\text { SKIN AND APPENDAGES: } \\
\text { Abrasion } \\
\text { Pruritus }\end{array}$ & $\begin{array}{l}1.3 \\
1.3\end{array}$ & $\begin{array}{l}0.0 \\
0.5\end{array}$ \\
\hline $\begin{array}{l}\text { UROGENITAL SYSTEM: } \\
\text { Impotence }\end{array}$ & 1.5 & 1.1 \\
\hline $\begin{array}{l}\text { SPECIAL SENSES: } \\
\text { Diplopia } \\
\text { Amblyopia }\end{array}$ & $\begin{array}{l}5.9 \\
4.2\end{array}$ & $\begin{array}{l}1.9 \\
1.1\end{array}$ \\
\hline $\begin{array}{l}\text { LABORATORY DEVIATIONS: } \\
\text { WBC Decreased }\end{array}$ & 1.1 & 0.5 \\
\hline
\end{tabular}

a Plus background antiepileptic drug therapy

Data from long-term, open, uncontrolled studies shows that Neurontin treatment does not result in any new or unusual adverse events.
Withdrawal From Treatment Due to Adverse Events

Approximately $6.4 \%$ of the 543 patients who received Neurontin in the placebo-controlled studies withdrew due to adverse events. In comparison, approximately $4.5 \%$ of the 378 placebo-controlled participants withdrew due to adverse events during these studies. The adverse events most commonly associated with withdrawal were somnolence (1.2\%), ataxia $(0.8 \%)$, fatigue, nausea and/or vomiting and dizziness (all at $0.6 \%$ )

\section{Other Adverse Events Observed in All Clinical Trials}

Adverse events that occurred in at least $1 \%$ of the 2074 individuals who participated in all clinical trials are described below, except those already listed in the previous table:

Body As a Whole

aesthenia, malaise, facial edema

Cardiovascular System

hypertension

Digestive System

anorexia, flatulence, gingivitis

Hematologic and

Lymphatic System

purpura; most often described as bruises resulting from physical

trauma

Musculoskeletal System

arthralgia

Nervous System

vertigo, hyperkinesia,

parasthesia, anxiety, hostility decreased or absent reflexes

Respiratory System

pneumonia

Special Senses

abnormal vision

\section{SYMPTOMS AND TREATMENT OF OVERDOSAGE}

Acute, life-threatening toxicity has not been observed with Neurontin (gabapentin) overdoses of up to 49 grams ingested at one time. In these cases, double vision, slurred speech, drowsiness, lethargy and diarrhea were observed. All patients recovered with supportive care.

Gabapentin can be removed by hemodialysis. Although hemodialysis has not been performed in the few overdose cases reported, it may be indicated by the patients clinical state or in patients with significant renal impairment.

Reduced absorption of gabapentin at higher doses may limit drug absorption at the time of overdosing and, hence, reduce toxicity from overdoses.

An oral lethal dose of gabapentin was not identified in mice and rats given doses as high as $8000 \mathrm{mg} / \mathrm{kg}$. Signs of acute toxicity in animals included ataxia, laboured breathing, ptosis, hypoactivity, or excitation.

\section{DOSAGE AND ADMINISTRATION}

Adults

The usual effective maintenance dose is 900 to $1200 \mathrm{mg} /$ day Treatment should be initiated with 300 to $400 \mathrm{mg} /$ day. Titration to an effective dose, in increments of $300 \mathrm{mg}$ or $400 \mathrm{mg} /$ day, can progress rapidly and can be accomplished over three days (see Table 3). Neurontin is given orally with or without food.

Table 3. Titration Schedule

\begin{tabular}{|c|c|c|c|}
\hline DOSE & Day 1 & Day 2 & Day 3 \\
\hline $900 \mathrm{mg} /$ day & $300 \mathrm{mg}$ OD & $300 \mathrm{mg}$ BID & $300 \mathrm{mg}$ TID \\
$1200 \mathrm{mg} /$ day & $400 \mathrm{mg}$ OD & $400 \mathrm{mg}$ BID & $400 \mathrm{mg}$ TID \\
\hline
\end{tabular}

Data from clinical trials suggest that doses higher than $1200 \mathrm{mg} /$ day may have increased efficacy in some patients; however, higher doses may also increase the incidence of adverse events (See Adverse Reactions).

Daily maintenance doses should be given in three equally divided doses (See Table 4), and the maximum time between doses in a three times daily schedule should not exceed 12 hours. It is not necessary to monitor gabapentin plasma concentrations in order to optimize Neurontin therapy. Further, as there are no drug interactions with commonly used antiepileptic drugs, Neurontin may be used in combination with these drugs without concern for alteration of plasma concentrations of either gabapentin or other antiepileptic drugs.

Table 4. Maintenance Dosage Schedule

\begin{tabular}{|c|r|}
\hline Total Daily Dose (mg/day) & Schedule \\
\hline 900 & $300 \mathrm{mg}$ TID \\
1200 & $400 \mathrm{mg}$ TID \\
1800 & $2 \times 300 \mathrm{mg}$ TID \\
2400 & $2 \times 400 \mathrm{mg}$ TID \\
\hline
\end{tabular}

Dosage adjustment in elderly patients due to declining renal function and in patients with renal impairment or undergoing hemodialysis is recommended as follows:

Table 5: Maintenance Dosage of Neurontin in Adults With Reduced Renal Function

\begin{tabular}{|c|c|c|}
\hline $\begin{array}{c}\text { Renal Function } \\
\text { Creatinine Clearance } \\
\text { (ml/min) }\end{array}$ & $\begin{array}{c}\text { Toial } \\
\text { Daily Dose } \\
\text { (mg/dayl }\end{array}$ & $\begin{array}{c}\text { Dose Regimen } \\
\text { (mg) }\end{array}$ \\
\hline$>60$ & 1200 & 400 Three times a day \\
$30-60$ & 600 & 300 Twice a Day \\
$15-30$ & 300 & 300 Once a Day \\
$<15$ & 150 & 300 Once Daily Every \\
Other Day \\
Hemodialysis $^{a}$ & - & $200-300^{b}$ \\
\hline
\end{tabular}

a Loading dose of 300 to $400 \mathrm{mg}$

b Maintenance dose of 200 to $300 \mathrm{mg}$ Neurontin following each 4 hours of hemodialysis

\section{Children Over 12 Years of Age}

The dosage used in a limited number of patients in this age group was $900-1200 \mathrm{mg} /$ day. Doses above $1200 \mathrm{mg} /$ day have not been investigated.

\section{AVAILABILITY OF DOSAGE FORMS}

Neurontin (gabapentin) capsules are supplied as follows:

\section{0-mg capsules;}

Hard gelatin SUPRO capsules with white opaque body and cap printed with "PD" on one side and "Neurontin/100 mg" on the other. Bottles of 100 capsules.

300-mg capsules;

Hard gelatin SUPRO ${ }^{\circ}$ capsules with yellow opaque body and cap printed with "PD" on one side and "Neurontin/300 mg" on the other. Bottles of 100 capsules.

400-mg capsules;

Hard gelatin SUPRO ${ }^{\oplus}$ capsules with orange opaque body and cap printed with "PD" on one side and "Neurontin/ $400 \mathrm{mg}$ " on the other. Bottles of 100 capsules.

\section{Composition}

Capsules contain gabapentin, lactose, corn starch, and talc. Capsule shells may contain gelatin, titanium dioxide, silicon dioxide, sodium lauryl sulfate, yellow iron oxide, red iron oxide, and FD\&C Blue No. 2

Stability and Storage Recommendations Store at controlled room temperature $15-30^{\circ} \mathrm{C}$

\section{NEW NEURONTIN Added SeIzUre Control...}

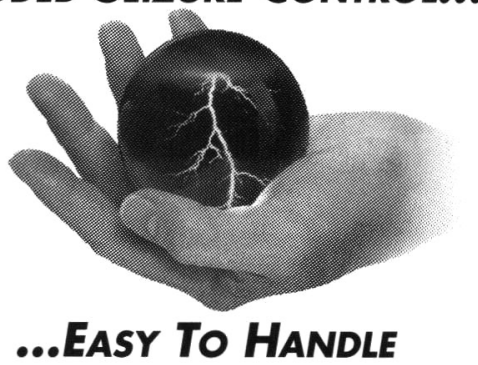

See page xiii.

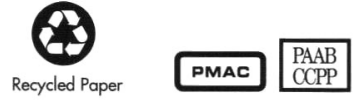

PARKE-DAVIS

Scarborough, Ontario, M1L 2N3 -T.M. Warner-Lambert Company, Parke-Davis
Division, Warner-Lambert Canada inc., auth. user. 


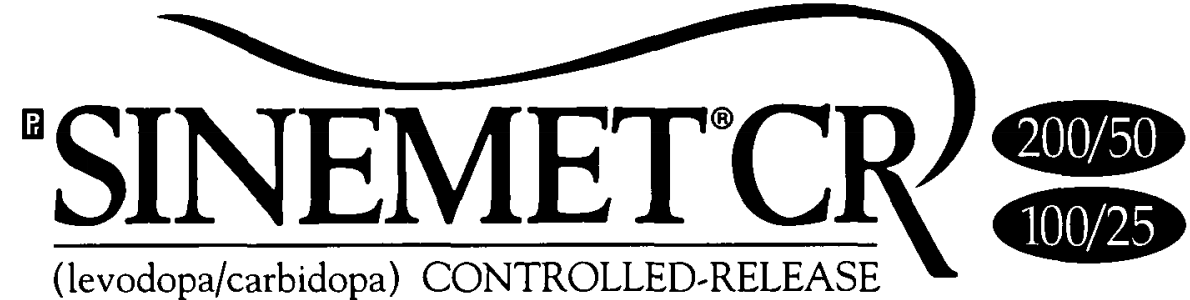

Controlled-Release Tablets

Antiparkinson Agent

Clinical Pharmacology: SINEMET ${ }^{\circ}$ CR (levodopa and carbidopa), a combination of levodopa, the metabolic precursor of dopamine and carbidopa, an aromatic amino acid decarboxylase inhibitor, is available in a polymer-based controlled-release tablet formulation. SINEMET(⿻) CR can be useful in reducing "off" time in patients treated previously with a conventiona levodopa/decarboxylase inhibitor combination who have had predictable peak dose dyskinesias and unpredictable motor fluctuations.

The symptoms of Parkinson's disease are related to depletion of dopamine in the corpus striatum. While the administration of dopamine is ineffective in the treatment of Parkinson's disease because it does not cross the blood-brain barrier, levodopa, the metabolic precursor of dopamine does cross the blood-brain barrier and is converted to dopamine in the basa ganglia. This is thought to be the mechanism whereby levodopa relieves the symptoms of Parkinson's disease.

Levodopa is rapidly decarboxylated to dopamine in extracerebral tissues so that only a small portion of a given dose is transported unchanged to the central nervous system. For this reason, large doses of levodopa are required for adequate therapeutic effect and these may otten be attended by nausea and other adverse reactions, some of which are altributable to dopamine formed in extracerebral tissues.

Carbidopa, a decarboxylase inhibitor, does not cross the blood-brain barrier and does not aftect the metabolism of levodopa within the centra nervous system. Since its decarboxylase inhibiting activity is limited to extracerebral tissues, administration of carbidopa with levodopa makes more levodopa avaliable for transport to the brain. Combined therapy with levedopa and carbidopa reduces the amount of levodopa required to optimum therapeutic benefit by about $75-80 \%$, permits an earlier response to therapy, and also reduces the incidence of nausea vomiting and cardiac arrhythmias. Combined therapy, however, does not decrease adverse reactions due to central effects of levodopa.

Following years of treatment with preparations containing levodopa, an increasing number of parkinsonian patients develop fluctuations in motor performance and dyskinesias. The advanced form of motor fluctuations ("on-off" phenomenon) is characterized by unpredictable swings from mobility to immobility. Although the causes of the motor fluctuations are not completely understood, it has been demonstrated that they can be attenuated by treatment regimens that produce steady plasma levels of levodopa

In clinical trials, patients with motor fluctuations experienced reduced "off" time with SINEMET ${ }^{\circledR}$ CR when compared with SINEMET ${ }^{\circledR}$. Global ratings of improvement and activities of daily living in the "on" and "off" slates, as assessed by both palient and physician, were slightly better in some patients during therapy with SINEMET ${ }^{\circ}$ CR than with SINEMET $\otimes$. In patients without motor lluctuations, SINEMET ${ }^{\circledR}$ CR provided therapeutic benefit similar to SINEMET but with tess frequent dosing.

Indications and Clinical Use: SINEMET ${ }^{\circ}$ (levodopa and carbidopa) is indicated for the treatment of Parkinson's disease.

At this time, experience in patients not previously treated with levodopa/decarboxylase inhibitors or levodopa alone is limited.

SINEMETO CR is not recommended for the treatment of drug-induced extrapyramidal reactions.

Contralndications: Monoamine oxidase inhibitors (except low doses of setective MA0-B inhibitors) and SINEMET ${ }^{\otimes}$ CR (levodopa and carbidopa) should not be given concomitantly. These inhibitors must be discontinued al least two weeks prios to initiating therapy with SINEMET $B$ CR.

SINEMET ${ }^{\otimes}$ CA should not be administered to patients with clinical of laboratory evidence of uncompensated cardiovascular, endocrine, hematologic. hepatic. pulmonary (including bronchial asthma), or renal disease; or o patients with narrow angle glaucoma

As with levodopa, SINEMET CR should not be given when administration of a sympathomimetic amine is contraindicated.

SINEMET ${ }^{\circ} C R$ is contraindicated in patients with known hypersensitivity to any component of this medication.

Because levodopa may activate a malignant melanoma, SINEMET ${ }^{\circ} \mathrm{CR}$ should not be used in patients with suspicious undiagnosed skin lesions or a history of melanoma.

Warnings: When patients are receiving levodopa monotherapy or SINEMET $\otimes$ (levodopa and carbidopa), this medication must be discontinued at least 8 hours before therapy with SINEMET $\odot$ CR is started (For appropriate dosage substilutions, see DOSAGE AND ADMINISTRATION

As with levodopa or SINEMET@. SINEMET@ CR may cause involuntary movements and mental disturbances. These reactions are thought to be due to increased brain dopamine following administration of levodopa. These adverse reactions may be more prolonged with SINEMETQ CR than with SINEMET\&. All patients should be observed caretully for the development of SINEMETO. All patients should be observed carefully for the development of
depression with concomitant suicidal tendencies. Patients with past or current psychoses should be treated with caution

A symptom complex resembling the neuroleptic malignant syndrome including muscular rigidity, elevated body temperature, mental changes. and increased serum creatine phosphokinase has been reported when antiparkinsonian agents were withdrawn abruptly. Therefore, patients should be observed caretully when the dosage of SINEMET ${ }^{\circ}$ CR is reduced abruptly or discontinued, especially it the patient is receiving neuroleptics.

(-)Trademark of Merck \& Co., Inc./Merck Frosst Canada Inc. and Du Pont Merck Pharma, R.U.
Care should be exercised in administering SINEMETB CR to patients with a history of recent myocardial intarction who have residual atrial nodal or ventricular arrhythmias. In such patients, cardiac function should be monitored with particular care during the period of initial dosage administration and titration, in a facility with provisions for intensive cardiac care.

SINEMET ${ }^{B}$ CR should be administered cautiously to patients with a history of peptic ulcer disease or of convulsions.

Precautions: General: Periodic evaluations of hepatic, hematopoietic cardiovascular and renal function are recommended during extended therapy (sEe ADVERSE REACTIONS)

Patients with chronic wide angle glaucoma may be treated cautiously with SINEMET ${ }^{\circ}$ CR (levodopa and carbidopa), provided the intraocula pressure is well controlled and the patient monitored carefully for changes

in intraocular pressure during therapy.
Use in Chitdren: Safety of SINEMET has not been established.

Use in Pregnancy and Lactation: Although the effects of SINEMET $\odot$ CR on human pregnancy and lactation are unknown, both levodopa and combinations of carbidopa and levodopa have caused visceral and skeleta malformations in rabbits (see TERATOLOGIC AND REPRODUCTIVE STUDIES). Therefore, use of SINEMET@ CR in women of child-bearing potential requires that the anticipated benefits of the drug be weighed against possible hazards to the mother and to the fetus. SINEMET ${ }^{\circledast}$ CA should not be given to nursing mothers.

Drug Interactions: Caution should be exercised when the following drugs are administered concomitantly with SINEMET $\odot$ CR:

Antihypertensive drugs: Symptomatic postural hypotension has occurred when levodopa/decarboxylase inhibitor combinations were added to the treatment of patients receiving antihypertensive drugs. Thereiore, when therapy with SINEMET $\otimes$ CR is started, dosage adjustment of the antihypertensive drug may be required.

Psychoactive dnugs: Phenothiazines and butyrophenones may reduce the therapeutic effects of levodopa. The beneficial effects of levodopa in Parkinson's disease have been reported to be reversed by phenytoin and papaverine. Patients laking these drugs with SINEMET. observed carefully for loss of therapeutic response.

There have been rare reports of adverse reactions, including hypertension and dyskinesia, resulting from the concomitant use of tricyclic antidepressants and carbidopa-levodopa preparations. (For patients receiving monoamine oxidase inhibitors, see CONTRAINDICATIONS.)

Other drugs: Although specitic interaction studies were not performed with other concomitant drugs, in clinical trials of SINEMETB CR patients were allowed to receive tricyclic antidepressants, benzodiazepines, propranolo thiazides, digoxin, $\mathrm{H}_{2}$ antagonists, salicylates and other nonsteroidal antiinflammatory drugs. SINEMET $\Theta C R$ was also used with other antiparkinson agents (see DOSAGE and ADMINISTRATION).

Adverse Reactions: In controlled clinical trials involvin 748 patients with moderate to severe motor fluctuations, SINEMET® $C R$ (levodopa and carbidopa) did not produce side effects which were unique to the controlled-release formulation.

The adverse reaction reported most frequently was dyskinesia $(12.8 \%)$ occasionally, prolonged, and at times, severe afternoon dyskinesias have occurred in some patients.

Other adverse reactions that were reported frequently were: nause $(5.5 \%)$, hallucinations $(5.3 \%)$, confusion ( $4.9 \%)$, dizziness $(3.5 \%)$, headache $(2.5 \%)$, depression $(2.5 \%)$, chorea $(2.5 \%)$, dry mouth $(2.3 \%)$ somnolence $(2.1 \%)$ dream abnormalities $(2.1 \%)$, dystonia $(2.0 \%)$ and asthenia $(2.0 \%)$.

Adverse reactions occurring less frequently (less than $2 \%$ ) were: System $/ \%$ : Body as a whote: Ches pain $1.7 \%$, Fatigue $0.9 \%$, Weight loss $0.8 \%$ Cardiovascular: Orthostatic hypotension $0.8 \%$, Palpitation $0.8 \%$, Hypotension $0.5 \%$.

Nervous System / Psychiatric: Insomnia 1.7\%, Falling 1.6\%, On-oft phenomenon $1.2 \%$, Paresthesia $0.9 \%$, Disorientation $0.8 \%$, Anxiety disorders $0.8 \%$, Decreased mental acuity $0.7 \%$. Extrapyramidal disorder $0.7 \%$ Gait abnormalities $0.7 \%$, Agitation $0.5 \%$, Memory impairment $0.5 \%$. Gastrointestinal: Anorexia 1.9\%. Constipation 1.5\%, Vomiting $1.3 \%$. Diarrhea $1.2 \%$, Gastrointestinal pain $0.9 \%$, Dyspepsia $0.8 \%$.

Musculosketelat: Muscle cramps $0.9 \%$.

Respiratory: Dyspnea $1.6 \%$

Special Senses: Blurred vision $1.1 \%$

0 ther adverse reactions that have been reported with levodopa or SINEMET and may be potential side effects with SINEMET $\otimes C R$ are listed below: Nervous System: Ataxia, numbness, increased hand tremor, muscle witching, blepharospasm, Irismus, activation of latent Horner's syndrome. Psychiatric: Sleepiness, euphoria, paranoid ideation and psychotic episodes, and dementia.

Cardiovascular: Arrhythmias, non-specific ECG changes, llushing, phlebitis Gastrointestinal: Bitter taste, sialorrhea, dysphagia, bruxism, hiccups, gastrointestinal bleeding, flatulence, burning sensation of tongue, development of duodenal ulcer.

Integumentary: Increased sweating, dark sweal, rash, hair loss. Genilourinary: Urinary frequency, retention, incontinence, hematusia, dark urine, nocturia and priapism.

Special Senses: Diplopia, dilated pupils, oculogyric crises

Hematologic: Leukopenia, hemolytic and non-hemolytic anemia, thrombocytopenia, agranulocytosis.
Miscellaneous: Weakness, taintness, hoarseness, malaise, hot flashes, sense of stimulation, bizarre breathing patterns, hypertension, neuroleptic malignant syndrome, malignant melanoma (see CONTRAINDICATIONS)

Convulsions have occurred; however, a causal relationship with evodopa or levodopa/carbidopa combinations has not been established.

Laboratory Tests: Laboratory tests which have been reported to be abnormal are alkaline phosphatase, SGOT (AST), SGPT (ALT), lactic dehydronenase bilirubin, and blood urea nitrogen.

Abnormalities in various laboratory tests have occurred with SINEMETE and may also occur with SINEMET $\otimes$ CR.

Carbidopa-levodopa preparations may cause a false-positive reaction lor urinary ketone bodies when a test tape is used for determination of ketonuria. This reaction will not be altered by boiling the urine specimen. Falsenegative lesis may result with the use of glucose-oxidase methods of testing for glycosuria.

Symptoms and Treatment of Overdosage: Management of acute Overdosage with SINEMETB CR (levodopa and carbidopa) is basically the same as management of acute overcosage with levodopa; however, pyridoxine is not effective in reversing the actions of SINEMETOCR.

Electrocardiographic monitoring should be instituted and the patient observed caretully for the development of arrtylthmias; if required, appropriate antiarrhythmic therapy should be given. The possiblity that the patient may have taken other drugs as well as SINEMET@ CR should be taken into consideration. To date, no experience has been reported with dialysis; hence, its value in overdosage is nol known.

Dosage and Administration: SINEMEI $\otimes$ CR (levodopa and carbidopa) Tablets contain a 4:1 ratio of levodopa to carbidopa. SINEMET@ CR 200/50 contains levodopa $200 \mathrm{mg} /$ carbidopa $50 \mathrm{mg}$ per tablet. SINEMET $\odot$ CR 100/25 contains levodopa $100 \mathrm{mg} /$ carbidopa $25 \mathrm{mg}$ per tablet. The daily dosage of SINEMEF ${ }^{\circ}$ CR must be determined by caretul titration. Patients should be monitored closely during the dose adjusiment period. particularly with regard 10 appearance or worsening of nausea or abnormal involuntary movements, including dyskinesias, chorea and dyslonia.

SINEMET@ CR 200/50 may be administered as whole or as hall tablets. SINEMETO CR 100/25 should only be administered as whole tablets. To maintain the controlled-release properties of the product, tablets should not be chewed or crushed.

Standard antiparkinson drugs, other than levodopa alone, may be continued while SINEMET $\odot$ CR is being administered, although their dosage may have to be adjusted. The delayed onset of action with SINEMET@ CR may require the supplemental use of conventional SINEMET@ Tablets for optimal control in the mornings.

Initial Dosage and Titration for Patients Currently Ireated with Conventional Levodopa/Decarboxylase Inhibitor Combinations: Dosage with SINEMETO CR 200/50 should be substituted at an amount that eventually provides approximately 10 to 30 percent more levodopa per day. The interval between doses should be prolonged by 30 to 50 percent. Initially, patients should receive SINEMET $\Theta$ CR 200/50 at a dosage that provides the same amount of levodopa, but with a longer dosing interval. Depending on clinical response, the dosage may be increased.

A guide for the initiation of treatment with SINEMETE CR 200/50 is shown in the following table:

Guideline for Initial Conversion from SINEMET $\Theta$ 10 SINEMET $\Theta$ CR 200/50

\begin{tabular}{|c|c|}
\hline $\begin{array}{l}\text { SINEMET@ } \\
\text { Total Daily Dose } \\
\text { Levodopa (mg) }\end{array}$ & $\begin{array}{l}\text { SINEMET@ CR 200/50 } \\
\text { (levodbpa } 200 \mathrm{mg} / \\
\text { carbidopa } 50 \mathrm{mg} \text { ) } \\
\text { Suggested Dosage Regimen }\end{array}$ \\
\hline $300-400$ & 1 tablet b.i.d. \\
\hline $500-600$ & $\begin{array}{l}11 / 2 \text { tablets bi.d. } \\
\text { or } 1 \text { tabiet ti.d. }\end{array}$ \\
\hline $700-800$ & $\begin{array}{l}\text { A tolal of } 4 \text { tablets in } \\
3 \text { or more divided doses } \\
\text { (e.g., } 11 \text { / } 2 \text { tablets a.m., } \\
11 / 2 \text { tablets early } p . m . \text {., } \\
\text { and } 1 \text { tablet later p.m.) }\end{array}$ \\
\hline $900-1000$ & $\begin{array}{l}\text { A total of } 5 \text { tablets in } \\
3 \text { or more divided doses } \\
\text { (e.g., } 2 \text { tablets a.m., } \\
2 \text { tablets early p.m., } \\
\text { and } 1 \text { tablet later p.m.) }\end{array}$ \\
\hline
\end{tabular}

" For dosing ranges not shown in the table, see DOSAGE AND ADMINISTRATION,

SINEMET $\otimes$ CR $100 / 25$ is available to facilitate titration when $100 \mathrm{mg}$ steps are required and as an alternative to the half tablet of SINEMETO CR 200/50.

Initial Dosage for Patients Currently Treated with Levodopa Alone: Levodopa must be discontinued at least eight hours before therapy with SINEMET $\otimes$ CR 200/50 is started. SINEMET $\odot$ CR should be substituted at dosage that will provide approximately $25 \%$ of the previous levodopa dosage. In patients with mild to moderate disease, the initial dose is usually 1 tablet of SINEMET $\odot$ CR 200/50 two times daily.

Patients Without Prior Levodopa Therapy: Experience with SINEMETO CR is limited in the de novo parkinsonian patients.

SINEMET $\otimes$ CR $100 / 25$ may be used in early stage patients who have not had prior levodopa therapy or to facilitate litration when necessary in patients receiving SINEMET (2) CR 200/50. The initial cecommended dose is 1 tablet of SINEMET ${ }^{\otimes}$ CR 100/25 twice daily. For patients who require more levodopa. a daily dose of 1104 tablets of SINEMET $\Theta$ CR $100 / 25$ wice a day is generally well-tolerated.

When appropriate, levodopa therapy may also be initiated with SINEMET $\otimes C R ~ 200 / 50$. The initial recommended dose in patients with mild to moderate disease is 1 tablet of SINEMET $\otimes$ CR 200/50 two times daily. Initial dosages should not exceed $600 \mathrm{mg}$ per day of levodopa or be given at intervals of less than 6 hours. 
If the divided doses of SINEMET ${ }^{(2)}$ CR 200/50 are nol equal, it is recommended that the smaller doses be given at the end of the day.

Maintenance: Because Parkinson's disease is progressive, periodic clinical evaluations are recommended and adjustment of the dosage regimen of SINEMET ${ }^{\otimes}$ CR may be required.

Addition of Other Antiparkinson Medications: Anticholinergic agents, dopamine agonisls, amantadine and lower doses of selective MAO-B inhibitors can be given with SINEMET@ CR. When combining therapies, dosage adjustments may be necessary.

Interruption of Therapy: Patients should be observed carefully if abrupt reduction or discontinuation of SINEMET $\otimes$ CR is required, especially it the patient is receiving neuroleptics (see PRECAUTIONS)

If general anesthesia is required. SINEMET CR may be continued as long as the patient is permitted to take oral medication. If therapy is interrupted temporarily, the usual dosage should be administered as soon as the patient is able to take oral medication.

Pharmaceutical Information

1. Drug Substance

Proper name:

Chemical name:

Levodopa

(-)-3-3 (3,4-

Dihydroxphenyl)-L-

levodopa and carbidopa

alanine.

\section{Carbidopa}

$(-)-L-\alpha-$ Hydrazino-3,4-

dinydroxy- $\alpha$-methy

hydrocinnamic acid

monohydrate.

Empirical formula:

$\mathrm{CgH}_{11} \mathrm{NO}_{4}$

Structural lormula:

$\mathrm{C}_{10} \mathrm{H}_{14} \mathrm{~N}_{2} \mathrm{O}_{4} \cdot \mathrm{H}_{2} \mathrm{O}$<smiles>NC(Cc1ccc(O)c(O)c1)C(=O)O</smiles><smiles>CC(Cc1ccc(O)c(O)c1)(NN)C(=O)O</smiles>

Molecular weight:

197.2

244.3

Tablet content is expressed in terms of anhydrous carbidopa, which has a molecular weight of 226.3

Description:

Levodopa, an aromatic amino

acid, is a white crystalline

compound, slightly soluble

in water.

Carbidopa, an inhibitor

of aromatic amino acid

decarboxylase is a white,

crystalline compound,

slightly soluble in wate

II. Composition

SINEMET $\otimes C R$ is a controlled-release formulation of levodopa and carbicopa in a ratio of $4: 1$. The tablet contains a polymer-based drug delivery system which controls the release of levodopa and carbidopa as it slowly erodes. Excipients include hydroxypropyl cellulose. NF and magnesium stearate, NF. SINEMET $\$$ CR 100/25 Tablets contain red lerric oxide, NF. SINEMET@ CR 200/50 Tablets contain red ferric oxide, NF and D\&C Yellow No. 10

III. Storage Recommendations

Store between $15^{\circ} \mathrm{C}\left(59^{\circ} \mathrm{F}\right)$ and $30^{\circ} \mathrm{C}\left(86^{\circ} \mathrm{F}\right)$. Protect trom sunlight.

Availability of Dosage Forms: No. 2042 - SINEMET CR 100/25 is

a pink-colored, oval-shaped, biconvex, compressed tablet, engraved

SINEMET CR on one side and 601 on the other. Available in bottles of 100

No. 2041 - SINEMET $\otimes$ CR is peach-colored, oval-shaped, biconvex, scored compressed tablet, engraved SINEMET CR on one side and $521 / 521$ on the other. Available in bottles of 100

Product Monograph Avallable on Request

(384-a,4,93)

04-94-SCR-93-CON-0040-JA

PAAB

2655 North Sheridan Way Mississauga, Ontario

\begin{tabular}{|l|}
\hline DUPONT \\
\hline PHARMA \\
\hline
\end{tabular}

See page xii.

IN EPILEPSY, ADD

${ }^{\prime}$ Frisium $_{10 \mathrm{mg}}$

TO ACHIEVE SEIZURE CONTROL

Frisium (clobazam) Tablets $10 \mathrm{mg}$

THERAPEUTIC CLASSIFICATION Anticonvulsant for adjunctive therapy. WDICATIONS Frisium (clobazam) has been found to be of value as adjunctive therapy in patients with epilepsy who are not adequately stabilized with their current anti-convulsant therapy. CONTRAINOICATIONS Hypersensitivity to clobazam, severe muscle weakness (myasthenia gravis) and narrow angle glaucoma WARNINGS Use in the elderly: Frisium (clobazam) should be used with caution in elderly and debilitated patients, and those with organic brain disorders, with treatment initiated at the lowest possible dose. [See Precautions]. Potentiation of drug effects: Patients should be cautioned about the possibility of additive effects when Frisium is combined with alcohol or other drugs with central nervous system depressant effects. Patients should be advised against consumption of alcohol during treatment with Frisium. [See Precautions]. Physical and psychological dependence: Physical and psychological dependence are known to occur in persons taking benzodiazepines. Caution must be exercised if it is at all necessary to administer Frisium to individuals with a history of drug misuse or those who may increase the dose on their own initiative. Such patients must be placed under careful surveillance. Signs and symptoms of withdrawal may follow discontinuation of use of Frisium; thus it should not be abruptly discontinued after prolonged use. [See Precautions]. Use in pregnancy: Frisium should not be used in the first trimester of pregnancy and thereafter only if strictly indicated. Nursing mothers in whom therapy with Frisium is indicated should cease breast-feeding since clobazam passes into breast milk. Several studies have suggested an increased risk of congenital malformations associated with the use of minor tranquilizers (chlordiazepoxide, diazepam and meprobamate) during the first trimester of pregnancy. If Frisium is prescribed to a woman of child-bearing potential she should be warned to consult her physician regarding the discontinuation of the drug if she intends to become, or suspects she might be, pregnant. Anterograde amnesia: Anterograde amnesia is known to occur after administration of benzodiazepines. Use in patients with depressio or psychosis: Frisium is not recommended for use in patients with depressive disorders or psychosis. PRECAUTIONS Driving and Hazardous Activities: Frisium (clobazam) possesses a mild central nervous system depressant effect therefore patients should be cautioned against driving, operating dangerous machinery of engaging in other hazardous activities, particularly in the dose adjustment period, or until it has been established that they do no become drowsy or dizzy. Use in the Elderly: Elderly and debilitate patients, or those with organic brain syndrome, have been found to be prone to the CNS depressant activity of benzodiazepines even after low doses. Manifestations of this CNS depressant activity include ataxia, oversedation and hypotension. Therefore, medication should be administered with caution to these patients, particularly if a drop in blood pressure might lead to cardiac complications. Initial doses should be low and increments should be made gradually, depending on the response of the patient, in order to avoid oversedation, neurological impairment and other possible adverse reactions. Dependence Liability: Frisium should not be administered to individuals prone to drug abuse. Caution should be observed in a patients who are considered to have potential for psychologica dependence. Withdrawal symptoms have been observed after abrupt discontinuation of benzodiazepines. These include irritability, nervousness, insomnia, agitation, tremors, convulsions, diarrhea, abdominal cramps, vomiting and mental impairment. As with other benzodiazepines, Frisium should be withdrawn gradually. Tolerance: Loss of part or all of the anti-convulsant effectiveness of clobazam has been described in patients who have been receiving the drug for some time. There is no absolute or universal definition for the phenomenon and reports vary widely on its development. The reported success of clobazam in intermittent therapy in catamenia epilepsy implies that tolerance may be minimized by intermitten treatment but long-term follow-up is unreported. No studies have identified or predicted which patients are likely to develop tolerance or precisely when this might occur. Use in Mental and Emotiona Disorders: It should be recognized that suicidal tendencies may be present in patients with emotional disorders; particularly those depressed. Protective measures and appropriate treatment may be necessary and should be instituted without delay. Since excitement and other paradoxical reactions can result from the use of benzodiazepines in psychotic patients, Clobazam should not be used in patients suspected of having psychotic tendencies. Use in Patients with Impaired Renal or Hepatic Function: Clobazam requires dealkylation and hydroxylation before conjugation. Usual precautions should be taken if Frisium is used in patients who may have some impairment of renal or hepatic function. It is suggested that the dose in such cases be carefully titrated. In patients for whom prolonged therapy with Frisium is indicated, blood counts and liver function should be monitored periodically. Use in Patients with Acule, Severe Respiratory Insufficiency: in patients with acute, severe respiratory insufficiency, respiratory function should be monitored. Laboratory Tests: If Frisium is administered for repeated cycles of therapy, periodic blood counts and liver and thyroid function iests are advisable. Drun Interactions: Most studies of the potential interactions of ciobazam with other anti-epileptic agents have failed to demonstrate significant interactions with phenytoin, phenobarbital, or carbamazepine. However, one study noted that the addition of clobazam caused a $25 \%$ increase in serum drug levels in $29 \%$ of patients taking carbamazepine, $63 \%$ of patients taking phenytoin, $13 \%$ of those taking vatproate and $14 \%$ of those on phenobarbital. The contradictory findings in different studies are presumably due to variations in patient susceptibility, and although clinically significant interactions are unusual, they may occur. Alcohol may also significantly increase plasma clobazam levels. Several of the established anti-epileptic agents: carbamazepine diphenylhydantoin, phenobarbital, valproic acid, cause the blood levels of clobazam to decrease slightly. Findings are less consistent with regard to $\mathrm{N}$-desmethytclobazam: serum levels are lower with concurrent valproic acid, but higher with carbamazepine and diphenylhydantoin. Toxicologic Studies: In mouse, clobazam was associated with hepatomas in high-dose males. In rat, an increased incidence of thyroid adenomas was seen in males. There were three malignancies: two (male and female) in the thyroid and one (female) in the liver. The relevance of these findings to man has not been established. ADVERSE REACTIONS from 19 published studies of Frisium (clobazam) use in epileptic patients, the overall incidence of side-effects was $33 \%$ of which drowsiness, dizziness and fatigue were most frequently reported. Canadian experience provides a similar overall incidence $(32 \%)$ with drowsiness reported in $17.3 \%$ of patients, and $12 \%$ of patients terminating treatment because of sideeffects. The incidence of side-effects was lower in patients under 16 years of age $(23.7 \%)$ than the incidence in adults $(43.1 \%): p<0.05$ whereas treatment discontinuation incidences were similar across age groups: $10.6 \%$ and $13.8 \%$ respectively. The following side-effects occurred at incidences of greater than $1 \%$ (ataxia [3.9\%], weight gain [2.2\%] dizziness [1.8\%], nervousness [1.6\%], behaviour disorder $[1.4 \%]$, hostility and blurred vision [1.3\%]) while other effects occurred at a less than $1 \%$ incidence. Symptoms of tiredness may sometimes appear, especially at the beginning of treatment with Frisium and when higher doses are used. Also in rare instances and usually only temporarily, the patient may experience dryness of the mouth, constipation, loss of appetite, nausea, dizziness, muscle weakness, disorientation, tiredness, or a fine tremor of the fingers, but also paradoxical reactions, e.g., restlessness and irritability. After prolonged use of benzodiazepines, impairment of consciousness combined with respiratory disorders has been reported in very rare cases, particularly in eiderly patients; it sometimes persisted for some length of time. Under experimental conditions, impairment of alertness has been observed to be less pronounced after therapeutic doses of clobazam than atter other benzodiazepines. Nevertheless, even when used as directed, the drug may alter reactivity to such an extent as to impair driving performance or the ability to operate machinery, especially when it is taken in conjunction with alcohol. As with other drugs of this type (benzodiazepines), the therapeutic benefit must be balanced against the risk of habituation and dependence during prolonged use. Isolated cases of skin reactions such as rashes or urticaria have been observed. DOSAGE AND ADMINISTAATION As with other benzodiazepines, the possibility of a decrease in anticonvuisant efficacy in the course of treatment must be borne in mind. In patients with impaired liver and kidney function Frisium (clobazam) should be used in reduced dosage. Adulis: Smail doses, $5-15 \mathrm{mg} /$ day, should be used initially, gradually increasing to a maximum daily dose of $80 \mathrm{mg}$ as necessary. Children: In infants ( 2 years), the initial daily dose is $0.5-1 \mathrm{mg} / \mathrm{kg} /$ day. The initial dose in children (2-16 years) should be $5 \mathrm{mg} /$ day, which may be increased at 5 -day intervals to a maximum of $40 \mathrm{mg} /$ day. As with all benzodiazepines, abrupt withdrawal may precipitate seizures. It is therefore recommended that Frisium be gradualyy reduced in dose before treatment is discontinued. Administration: if the daily dose is divided, the higher portion should be taken at night. Daily doses up to $30 \mathrm{mg}$ may be taken as a single dose at night. AVAILABILITY Frisium is available as white, uncoated, bevelled, round tablets of $7 \mathrm{~mm}$ diameter, marked with 'BGL' above and Delow the scorebreak on the obverse and the Hoechst 'Tower and Bridge' logo on the reverse. Frisium $10 \mathrm{mg}$ tablets are packaged in blisters of PVC film and aluminium foil and are distributed in packs of 30 [3×10] tablets. Product Monograph available on request.

Reference: 1. Clobazam in the Treatment of Refractory Epilepsy - The Canadian Experience. A Retrospective Study, Canadian Clobazam Cooperative Group: Epilepsia, 1990;1-10. FRI 2698/9053E

See pages ibc, iii.

PAAB

7. Hoechst and $\Theta$, Reg. Trademarks of Hoechst AG, Germany

Hoechst Canada Inc., Montreal H4R 2E8

Hoechst $\mathrm{B}$ 

Intermediate Prescribing Information

PTEGRETOL ${ }^{\oplus}$ (cartamazepine tabless) TEGAETOLO $200 \mathrm{mg}$

ETEGRETOL Chewtabs ${ }^{\circ}$

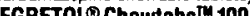

TEGAETOLO Chewtabs $200 \mathrm{mg}$

PTEGRETOL ${ }^{\circ}$ CR

TEGRETOL ${ }^{\circ}$ CR $200 \mathrm{mg}$ TEGRETOL ${ }^{\circ}$ CR $400 \mathrm{mg}$ Anticonvulsant

For symptomatic relief of trigeminal neuralgia

Antimanic

INDICATIONS A. Management of psychomotor (temporal lobe) epilepsy. As an adjunct in some patients with secondary or partial epilepsy with complex symptomatology or second. arily generalized seizures, when combined with other antiepileptic agents.

As an alternative in patients with generalized tonic-clonic seizures and marked side effects or who tail to respond to other anticonvulsant drugs.

Ineffective for controlling petit mal, minor motor, myoclonic and predominantly unilateral seizures, and does not prevent generalization of epileptic discharge. Exacerbation of seizures may occur in patients with atypical absences.

B. Symptomatic relief of pain of true or primary trigeminal neuralgia (tic douloureux). Not for prophylactic use. Glossopharyngeal neuralgia has been relieved in some patients. Other measures must be considered for patients failing to respond or who are sensitive to TEGRETOL.

C. Treatment of Acute Mania and Prophylaxis in Bipolar (Manic-Depressive) Disorders: may be used as monotherapy or adjunct to lithium in patients who are resistant to or are intolerant of conventional antimanics. Possibly an alternative to neuroleptics in such patients. Patients with severe mania, dysphoric mania or rapid cycling who are non-responsive to thium may respond positiv mendations are based on extensive clinicar exp some comparative trials

CONTRAINDICATIONS History of hepatic disease, acute intermittent porphyria or serious blood disorder, in patients with AV heart block (see Precautions), hypersensitivity to carbamazepine or to tricyclic compounds, or their analogues or metabolites.

Do not give with, immediately before or immediately after treatment with monoamine oxidase inhibitors. There should be as long a drug free interval as the clinical condition allows, in no case less than 14 days. Then TEGRETOL dosage should be low initially, increased very gradually.

WARNINGS Although reported intrequently, serious adverse effects have been observed during use of TEGRETOL (carbamazepine). Agranulocytosis and aplastic anemia have occurred in a few instances with a latal outcome. Leucopenia, thrombocytopenia, hepatocellular and choles. latic faundice, and hepatitis also reported. It is importan! that TEGRETOL be used carefully and close cllnical and trequent laboratory supervision be maintained throughout treatment to detect signs and symptoms of possible blood dyscrasla, as eanty as possible. Discontinue TEGRETLL if any evidence of signiffcant bone marrow depression appears. (See "PRECAUTIONS"). Should signs and symptoms suggest a severe skin reaction such as Steven Johnson syndrome or Lyell's syndrome, withdraw TEGRETOL at once. Long-term toxicity studies in rats indicated a potential carcinogenic risk. Welgh possible risk of TEGRETOL against potential benefits before prescribing.

Pregnancy and nursing: Women with epilepsy who are, or intend to become pregnant, should be treated with special care.

In women of childbearing potential, TEGRETOL (carbamazepine) should, whenever possible, be prescribed as monotherapy, because the incidence of congenital abnormalities in offspring of women treated with more than one antiepileptic drug is greater than in those receiving single antiepileptic. Minimum effective doses should be given and plasma levels monitored.

If woman receiving TEGRETOL becomes pregnant, or if the problem of initiating TEGRETOL arises during pregnancy, weigh the drug's potential benefits against its hazards, particularly during the first 3 months of pregnancy. Do not discontinue TEGRETOL or withhold from patients if required to prevent major seizures because of the risks posed, to both mother and fetus, by status epilepticus with attendant hypoxia.

Possibility that carbamazepine, like all major antiepileptic drugs, increases the risk of malformations has been reported. Rare reports on developmental disorders and malformations, including spina bifida, in association with carbamazepine. Conclusive evidence from controlled studies with carbamazepine monotherapy is lacking.

Folic acid deficiency is known to occur in pregnancy. Antiepileptic drugs have been reported to aggravate folic acid deficiency, which may contribute to increased incidence of birth defects in offspring of treated epileptic women. Folic acid supplementation is recommended before and during pregnancy.

Vitamin $K_{1}$ administration to mother during last weeks of pregnancy, and to newborn, has been recommended to prevent neonatal bleeding disorders.

Carbamazepine passes into breast milk in concentrations of about $25-60 \%$ of the plasma level. No reports available on long-term effect of breast feeding. Weigh benefits of breast feeding against possible risks to infant. Observe infant for possible adverse reactions, e.g., somnolence, should mother taking carbamazepine nurse.

A severe hypersensitivity skin reaction in a breast-fed baby has been reported.

Reliability of oral contraceptives may be adversely affected by carbamazepine (see PRECAUTIONS, Drug Interactions). PRECAUTIONS Clinical Monitoring of Adverse Reactions: Prescribe TEGRETOL only after a critical risk-benefit appraisal in patients with a history of cardiac, hepatic or renal damage, adverse haematological reactions to other drugs, or interrupted courses of therapy with TEGRETOL. Maintain careful clinical and laboratory supervision throughout treatment. Should any signs or symptoms or abnormal laboratory findings be suggestive of blood dyscrasia or liver disorder, discontinue TEGRETOL immediately until case is carefully reassessed.

(a) Bone marrow function: Carry out complete blood counts including platelets and possibly reticulocytes and serum iron before treatment is instituted. Suggested guidelines for monitoring are weekly for the first month, monthly for the next 5 months, thereafter 2-4 times/year

If definitely low or decreased white blood cell or platelet counts are observed during treatment, patient and complete blood count should be monitored closely. Non-progressive fluctuating asymptomatic leucopenia encountered, does not generally call for TEGRETOL withdrawal. However, treatment should be discontinued if the patient develops leucopenia which is progressive or accompanied by clinical manifesta tions, e.g. fever or sore throat, which could indicate onset of significant bone marrow depression.

Because onset of potentially serious blood dyscrasias may be rapid, patients should be made aware of early toxic signs and symptoms of potential hemalological problem. and symptoms of dermatological or hepatic reactions. reactions, e.g. fever, sore throat, rash, ulcers in mouth, easy bruising. petechial or purpuric hemormage appear, advise patient to consult his/her physician immediately.

(b) Hepatic function: Baseline and periodic evaluations of hepatic function must be performed, particularly in elderly patients and those with history of liver disease. Withdraw TEGRETOL immediately in cases of aggravated liver dysfunction or active liver disease.

(c) Kidney function: Perform pretreatment and periodic comolete urinalysis and BUN determinations.

(d) Ophthalmic examinations: Carbamazepine has been as sociated with pathological eye changes. Periodic eye examinations, including slit-lamp funduscopy and tonometry recommended.

(e) Plasma levels: Although correlations between dosage and plasma levels, and between plasma levels and clinical efficacy or tolerability are rather tenuous, monitoring plasma levels may be useful in the following conditions: dramatic increase in seizure frequency/verification of patient compliance; pregnancy; when treating children or adolescents; suspected absorption disorders; suspected toxicity, especially where more than one drug is used (see "Interactions")

Increased Seizure Frequency: Use TEGRETOL with caution in patients with mixed seizure disorder that includes atypical absence seizures, since use has been associated with increased trequency of generalized convulsions. In case of exacerbation of seizures, discontinue TEGRETOL.

Dermatologic: Mild skin reactions, e.g., isolated macular or maculopapular exanthema, usually disappear within a few days or weeks, either during continued course of treatment or following dosage decrease. However, patient should be kept under close surveillance because of rare possibility of StevenJohnson syndrome or Lyell's syndrome occurring (see WARNINGS)

Urinary Retention and Increased Intraocular Pressure: Because of its antichotinergic action, carbamazepine should be given cautiously, if at all, to patients with increased intraocular pressure or urinary retention. Follow such patients closely while on the drug.

Occurrence of Behavioural Disorders: Because it is closely related to other tricyclic drugs, there is a possibility that carbamazepine might activate latent psychosis, or, in elderly patients, produce agitation or confusion, especially when combined with other drugs. Exercise caution in alcoholics.

Use in Patients with Cardiovascular Disorders: Use TEGRETOL cautiously in patients with history of coronary artery disease, organic heart disease, or congestive failure. If defective conductive system suspected, perform an ECG before administering TEGRETOL, to exclude patients with atrioventricular block.

Driving and Operating Hazardous Machinery: Because dizjness and drowsiness are possible side effects of TEGRETOL warn patients about possible hazards of operating machinery or driving automobiles.

Drug Interactions: Induction of hepatic enzymes in response to carbamazepine may diminish or abolish activity of certain drugs also metabolized in the liver. Dosage of the following drugs may have to be adjusted: clobazam, clonazepam, ethosuximide, primidone, valproic acid, alprazolam, corticosteroids (e.g. prednisolone, dexamethasone) cyclosporin digoxin, doxycycline, felodipine, haloperidol, thioridazine, imipramine, methadone, oral contraceptives, theophylline, and oral anticoagulants (wartarin, phenprocoumon, dicumarol) Phenytoin plasma levels reported to be both raised and lowered by carbamazepine, and mephenytoin plasma levels reported to increase in rare instances.

The following drugs have been shown to raise plasma carbamazepine levels: enthromycin troleandomycin possibly osamycin, isoniazid, verapamil, diltiazem, propoxyphene viloxazine, fluoxetine, cimetidine, acetazolamide, danazol and possibly desipramine. Nicotinamide raises carbamazepine plasma levels in children, but only at high dosage in adults. Since an increase in carbamazepine plasma levels may result in unwanted effects (e.g. dizziness, drowsiness, ataxia, diplopia and nystagmus), adjust TEGRETOL dosage accordingly and monitor the blood levels.

Plasma levels of carbamazepine may be reduced by phenobarbitone, phenytoin, primidone, progabide, or theophylline and possibly by clonazepam. Alternatively, valproic acid, valpromide, and primidone have been reported to raise plasma levels of pharmacologically active metabolite, carbamazepine-10, 11 epoxide. TEGRETOL dose may consequently require adjustment.

Combined use with lithium, metoclopramide, or haloperidol may increase risk of neurotoxic side effects (even in presence of "therapeutic plasma levels").

Concomitant use with isoniazid reported to increase isoniazid induced hepatotoxicity.

TEGRETOL, like other anticonvulsants, may adversely affect the reliability of oral contraceptives; breakthrough bleeding may occur. Patients should accordingly be advised to use some alternative, non-hormonal method of contraception. Concomitant medication with TEGRETOL and some diuretics (hydrochlorothiazide, furosemide) may lead to symptomatic hyponatremia.

TEGRETOL may antagonize effects of non-depolarising muscle relaxants (e.g. pancuronium); their dosage may need to be raised and patients should be monitor blockade than expected.

Isotretinoin reported to alter the bioavailability and/or clearance of carbamazepine and its active 10, 11-epoxide; carbamazepine plasma levels should be monitored.

Carbamazepine, may reduce tolerance to alcohol; advisable to abstain from alcohol consumption during treatment.

TEGRETOL should not be administered in conjunction with MAO inhibitor. (SEe CONTRAINDICATIONS).

AOVERSE REACTIONS Reactions most frequently reported are CNS (e.g. drowsiness, headache, unsteadiness on feet diplopia, dizziness), gastrointestinal disturbances (nausea vomiting), and allergic skin reactions. These reactions usually occur only during the initial phase of therapy, if initial dose is too high, or when treating elderly patients. They have rarely necessitated discontinuing TEGRETOL therapy, and can be minimized by initiating treatment at low dosage.

Occurrence of CNS adverse reactions may be manifestation of relative overdosage or significant fluctuation in plasma levels. In such cases it is advisable to monitor plasma levels and possibly lower daily dose and/or divide it into 3-4 fractional doses.

More serious adverse reactions observed are hematologic hepatic, cardiovascular and dermatologic reactions, which require discontinuation of therapy. If treatment is to be with drawn abruptly, effect the change-over to another antiepileptic under cover of diazepam.

Adverse reactions reported:

Hematologic: Occasional or frequent - leucopenia; occasional - eosinophilia, thrombocytopenia; rare - leucocytosis, lymphadenopathy; isolated cases - agranulocytosis, aplastic anemia, pure red cell aplasia, macrocytic anemia, acute intermittent porphyria, reticulocytosis, folic acid deficiency, thrombocytopenic purpura, and possi

Hepatic: Frequent - elevated gamma-GT (due to hepatic enzyme induction), usually not clinically relevant; occasional - elevated alkaline phosphatase; rarely - transaminases; rare - jaundice, hepatitis of cholestatic, parenchymal, hepatocellular, or mixed type; isolated cases - granulomatous hepatitis

Dermatologic: Occasional to frequent - skin sensitivity reac tions and rashes, erythematous rashes, urticaria; rare exfoliative dermatitis and erythroderma, Steven-Johnson syndrome, systemic lupus erythematosus-like syndrome; isolated cases - toxic epidermal necrolysis (Lyell's syndrome) photosensitivity, erythremia multiform and nodosum, skin pigmentation changes, pruritus, purpura, acne, diaphoresis, alopecia and neurodermatitis.

Neurologic: Frequent - vertigo, somnolence, ataxia and tatique. Occasionally - an increase in motor seizures (see INDICATIONS), headache, diplopia, nystagmus, accommodation disorders (e.g. blurred vision); rare - abnormal involuntary disorders (e.g. tremor, asterixis, orofacial dyskinesia, choreoathetosis disorders, dystonia, tics); isolated cases oculomotor disturbances, speech disorders (e.g. dysarthria or slurred speech), peripheral neuritis, paraesthesiae. There have been some reports of paralysis and other symptoms of cerebral arterial insufficiency but no conclusive relationship to the administration of TEGRETOL could be established. Cardiovascular: Disturbances of cardiac conduction, brady cardia, arrhythmias, Stokes-Adams in patients with AV-block congestive heart failure, hypertension or hypotension, aggra- 
Genitourinary: Isolated cases - interstitial nephritis and renal failure, as well as signs of renal dysfunction (e.g. albuminuria glycosuria hematuria, oliguria sometimes associated with elevated blood pressure, and elevated BUN/azotemia), urinary frequency, urinary retention, and renal failure.

Isolated reports - sexual disturbances/impotence.

Gastrointestinal: Occasional or frequent - nausea, vomiting Occasional: dryness of the mouth and throat; rare - diarrhoea or constipation; isolated cases - abdominal pain, glossitis, stomatitis, anorexia.

Sense Organs: Isolated cases - lens opacities, conjunctivitis, retinal changes, tinnitus, hyperacusis, and taste disturbances. Endocrine System and Melabolism: Occasionally edema fluid retention, weight increase, hyponatremia and reduced plasma osmolality due to antidiuretic hormone (ADH)-like effect, leading in solated cases to water intoxication accom panied by lethargy, vomiting, headache, mental confusion, neurological abnormalities Isolated cases of gynecomastia or galactorrhea have been reported, as well as abnormal thyroid function tests (decreased L-thyroxine, i.e., $\mathrm{FT}_{4}, T_{4}, T_{3}$, and increased TSH, usually without clinical manifestations), dis turbances of bone metabolism (decrease in plasma calcium and $25-0 \mathrm{H}$-calciferol), leading in isolated cases to osteomalacia, as well as reports of elevated levels of cholesterol, including HDL cholesterol and triglycerides.

Musculoskelelal System: Isolated cases - arthralgia, muscle pain or cramp.

Respiratory: Isolated cases - pulmonary hypersensitivity characterize by fever, dyspnea, pneumonitis or pneumonia. Hypersensitivity reactions: Rare delayed multi-organ hypersensitivity disorder with fever, skin rashes, vasculitis, lympha denopathy, disorders mimicking lymphoma, arthralgia leucopenia, eosinophilia, hepato-splenomegaly and abnorma liver function tests, occurring in various combinations. Othe organs may also be affected (e.g. lungs, kidneys, pancreas, myocardium).

Isolated cases: aseptic meningitis, with myoclonus and eosinophilia; anaphylactic reaction. Treatment should be dis-

continued should such hypersensitivity reactions occur.
SYMPTOMS AND TREATMENT OF OVERDOSAGE Lowest Known Lethal Dose: estimated $3.2 \mathrm{~g}$ ( 24 year old woman) Highest known doses survived: $80 \mathrm{~g}$ ( 34 year old man); $34 \mathrm{~g}$ (13 year old girl); $1.4 \mathrm{~g}$ (23 month old girl).

Symptoms of Overdosage: The presenting signs and symptoms of overdosage usually involve the central nervous, cardiovascular, and respiratory systems.

Central Nervous System: CNS depression, disorientation, tremor, restlessness, somnolence, agitation, hallucination, coma, blurred vision, nystagmus, mydriasis, slurred speech dysarthria, ataxia, dyskinesia, abnormal reflexes (slow) hyperactive), convulsions, psychomotor disturbances, myoclonus, opisthotonia, hypothermia/hyperthermia, flushed clonus, opisthotonia, hypother

Respiratory System: Respiratory depression, pulmonary edema.

Cardiovascular System: Tachycardia, hypotension/hypertension, conduction disturbance with widening of QRS complex, syncope in association with cardiac arrest.

Gastrointestinal System: Nausea, vomiting, delayed gastric emptying, reduced bowel motility.

Renal Function: Urinary retention, oliguria or anuria; fluid retention, and water intoxication.

Laboratory Findings: Hyponatremia, hypokalemia, leukocytosis, reduced white cell count, metabolic acidosis, hyperglycemia, glycosuria, acetonuria, increased muscle creatinine phosphokinase.

Treatment of Overdosage: There is no known specific antidote to TEGRETOL (carbamazepine).

Evacuate the stomach, with an emetic or by gastric lavage then administer activated charcoal.

Observe vital signs and administer symptomatic treatment as required. Hyperirritability or convulsions may be controlled by the administration of parenteral diazepam or barbiturates but they may induce respiratory depression, particularly in children. Paraldehyde may be used to counteract muscular hypertonus without producing respiratory depression.

When barbiturates are employed, it is advisable to have equipment available for artificial ventilation and resuscitation. Barbiturates should not be used if drugs that inhibit monoamine oxidase have been taken by the patient, either in overdosage or in recent therapy (within two weeks)

Hyponatremia should be treated by restricting fluids and a slow and careful $\mathrm{NaCl} 0.9 \%$ infusion i.v. These measures may be useful in preventing brain damage.

Shock (circulatory collapse) should be treated with supportive measures, including intravenous fluids, oxygen, an corticosteroids. For hypotension unresponsive to measures taken to increase plasma volume, dopamine or dobutamine i.v. may be administered.

It is recommended that ECG be monitored, particularly in children, to detect cardiac arrhythmias or conduction defects. Charcoal hemoperfusion has been recommended. Forced diuresis, hemodialysis, and peritoneal dialysis reported to be ineffective.

Relapse and aggravation of the symptomatology on the 2 nd or 3rd day after overdose, due to delayed absorption, should be anticipated.

DOSAGE AND ADMINISTRATION Use in Epilepsy (See INDICATIONS): Low initial daily dosage of TEGRETOL (carbamazepine) with a gradual increase in dosage is advised. Adjust dosage to the needs of the individual patient.

TEGRETOL tablets and CHEWTABS should be taken in 2 to 4

divided doses daily, with meals when possible.
Controlled release characteristics of TEGRETOL CR reduce Che daily fluctuations of plasma carbamazepine TEGRETOL CR tablets (either whole or, if so prescribed, half a tablet) should be swallowed unchewed with a little liquid during or after a meal. Controlled release tablets should be prescribed as a b.i.d. dosage. If necessary, 3 divided doses may be prescribed

Adults and Children Over 12 Years: Initially, 100 to $200 \mathrm{mg}$ once or twice a day depending on the severity of the case and previous therapeutic history. Initial dosage is progressively increased in divided doses until best response is obtained Usual optimal dosage is 800 to $1200 \mathrm{mg}$ daily. In rare instances some adult patients have received $1600 \mathrm{mg}$. As soon as disappearance of seizures has been obtained and maintained, reduce dosage very gradually until reaching minimum effective dose.

Children 6-12 Years: Initially, $100 \mathrm{mg}$ in divided doses on firs day Increase gradually by adding $100 \mathrm{mg} /$ day until best response is obtained. Dosage should generaliy not exceed $1000 \mathrm{mg}$ daily. As soon as disappearance of seizures has been obtained and maintained, reduce dosage very gradually until reaching minimum effective dose.

Use in Trigeminal Neuralgia: Initial daily dosage $200 \mathrm{mg}$ taken in 2 doses of $100 \mathrm{mg}$ is recommended. Total daily dosage can be increased by $200 \mathrm{mg} /$ day until relief of pain is obtained, usually achieved at dosage $200-800 \mathrm{mg}$ daily: occasionally up to $1200 \mathrm{mg} /$ day necessary. As soon as relie of pain has been obtained and maintained, attempt progressive reduction in dosage until reaching minimal effective dosage. Because trigeminal neuralgia is characterized by periods of remission, attempts should be made to reduce or discontinue the use of TEGRETOL at intervals of not more than 3 months, depending on individual clinical course.

Prophylactic use in trigeminal neuralgia is not recommended. Use In Mania and Bipolar (Manic Depressive) Disorders: Low initial dosage of $200-400 \mathrm{mg} / \mathrm{day}$, in divided doses, higher starting doses of $400-600 \mathrm{mg} /$ day may be used in acute mania. May be gradually increased until symptomatology is controlled or a total daily dose of $1600 \mathrm{mg}$. Adjust dosage increments for optimal tolerability. Usual dose is 400 . $1200 \mathrm{mg} /$ day in divided doses. For maintenance, continue with doses used to achieve optimal acute responses and tolerability. In combination with lithium, neuroteptics: initially a low dosage of $100-200 \mathrm{mg} /$ day; gradually increase. Daily dose $>800$ mg is rarely required when given in combination with neuroleptics, lithium or other psychotropics, e.g., benzo-
diazepines. Plasma levels are probably not helpful for guiddiazepines. Plasma levels

AVAILABILITY TEGRETOL Tablets $200 \mathrm{mg}$ : Each white round, flat, bevelled-edge double-scored tablet engraved GEIGY on one side contains $200 \mathrm{mg}$ carbamazepine. Protect from heat (store below $30^{\circ} \mathrm{C}$ ) and humidity. Bottles of $100 /$ 500. TEGRETOL CHFWTABS $100 \mathrm{mg}$ : Pale pink round flat bevelled-edge tablets with distinct red spots. GEIGY engraved on one side and MR on the other. Fully bisected between the $M$ and R. Each contains $100 \mathrm{mg}$ carbamazepine. Protect from heat (store below $30^{\circ} \mathrm{C}$ ), light and humidity. Bottles of 100 TEGRETOL CHEWTABS $200 \mathrm{mg}$ : Pale pink, oval, biconvex tablets with distinct red spots. GEIGY engraved on one side and PU engraved on the other. Fully bisected between the $P$ and U. Each contains $200 \mathrm{mg}$ carbamazepine. Protect from heat (store below $30^{\circ} \mathrm{C}$ ), light and humidity. Bottles of 100 TEGRETOL CR $200 \mathrm{mg}$ : Beige-orange, oval, slightly biconvex tablet, engraved CG on one side and $\mathrm{HC}$ on the other. Fully bisected on both sides. Each contains $200 \mathrm{mg}$ carbamazepine. Protect from heat (store below $25^{\circ} \mathrm{C}$ ) and humidity. Bottles of 100. TEGRETOL CR $\mathbf{4 0 0} \mathbf{m g}$ : Brownish-orange, oval, slightly biconvex tablet, engraved CG/CG on one side and ENE/ENE on the other. Fully bisected on both sides. Each contains $400 \mathrm{mg}$ carbamazepine. Protect from heat (store below $25^{\circ} \mathrm{C}$ ) and humidity. Bottles of 100 . TEGRETOL is available to patients only by prescription.

Product Monograph available on request.

January 4, 1993 REFERENCES

1. Smith DB, et al: Results of a nationwide Veterans Administration cooperative study comparing the efficacy and toxicity of carbamazepine, phenobarbital, phenytoin, and primidone. Epilepsia 1987; 28(Supp| 3): 550-558

2. Dooley JM: Seizures in childhood. Medicine North America 1989: 4th series 2: 163-172.

3. Aldenkamp AP, et al: Controlled release carbamazepine: cognitive side effects in patients with epilepsy. Epilepsia 1987: $28(5): 507-514$

4. Canger $R$, et al: Conventional vs controlled-release carbamazepine: a multicentre, double-blind, cross-over study. Acta Neurol Scand 1990; 82: 9-13.

See pages obc, $x v$.

Geigy

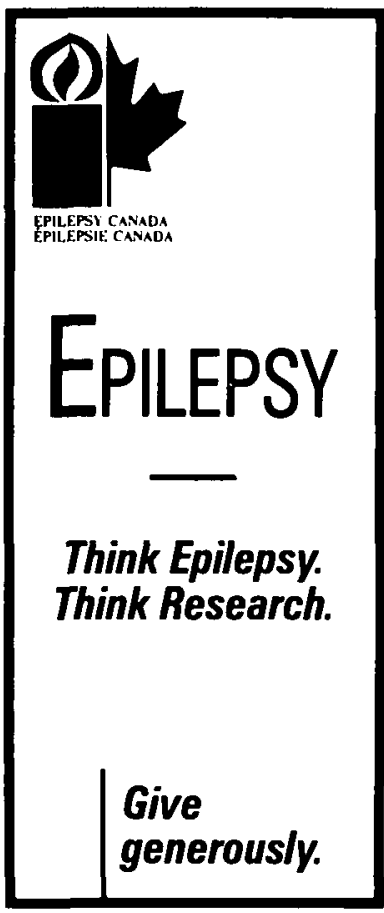

Copies of articles from this publication are now available from the UMI Article Clearinghouse.

Yes! I would like to know more about UMI Article Clear-

inghouse. I am interested in electronic

ordering through the following systemisi:

$\square$ DLALOG/Dialorder $\quad \square$ ITT Dialcom

$\square$ Ontyme $\square$ OCLC ILL Subsystem

Other (please specify)

$\square$ Please send me your current catalog and user instruc.

tions for the system(s) i checked above.

Name

Title

Institution/Company

Departmen:

Address

City___ State___ Zip

Phone 1

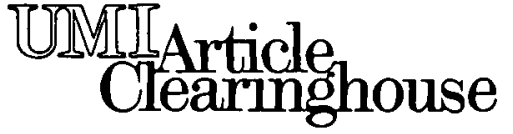

Mail to: University Microfilms Internationa 300 North Zeeb Road, Box 91 Ann Arbor, MI 48106 
PRESCRIBING INFORMATION

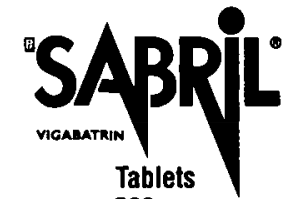

$500 \mathrm{mg}$

Antiepileptic

ACTION AND CLINICAL PHARMACOLOGY

SABRIL (vigabatrin) is an irreversible inhibitor of gamma-aminobuyyric acid transaminase (GABA-T), the enzyme responsible for the catabolism of the inhibitory neurotransmitter gamma-aminobutyric acid (GABA) in the brain. The mechanism of action of vigabatrin is attributed to irreversible enzyme inhibition of GABA-T, and consequent increased levels of the inhibitory neurotransmitter, GABA. Decreased serum levels of SGOT (ALT) and SGPT (AST) have been observed during treatment with vigabatrin and may be the result of inhibition of these transaminases by vigabatrin. The clinical significance of these findings is unknown.

The duration of effect of vigabatrin is thought to be dependent on the rate of GABA-T resynthesis rather than on the plasma concentration of vigabatrin.

\section{Clinical Trials}

In clinical triats, including double-blind, placebo-controlled studies involving 354 patients with drug-resistant complex partial seizures, vigabatrin reduced seizure frequency by $50 \%$ or more in approximately half of the patients studied.

In clinical trials involving children, the efficacy of vigabatrin was similar to that seen in adult patients with refractory partial seizures. In one study of 70 children with intractable infantile spasms, approximately $70 \%$ of the patients had a greater than $50 \%$ reduction in spasms. In this study, long-term response was observed in $75 \%$ of the children with symptomatic intantile spasms and $36 \%$ of the children with cryptogenic infantile spasms.

Pharmacokinetics

Vigabatrin is rapidfy absorbed following oral administration and peak plasma concentrations are reached within two hours. Vigabatrin is widely distributed with an apparent volume of distribution slightly greater than total body water. The primary route of elimination is via the kidney, with little metabolic transformation occurring. Following a single dose, approximately $70 \%$ is excreted in the urine as unchanged drug within the first 24 hours post-dose. The plasma elimination half-life is approximately 5-8 hours in young adults and 12-13 hours in the elderly. In renal impairment the elimination is prolonged and the rate of renal clearance is directly related to creatinine clearance (see PRECAUTIONS and DOSAGE AND ADMINISTRATION) Vigabatrin does not induce the hepatic cytochrome P450 system nor is it extensively metabolized or plasma-protein bound. Administration of vigabatrin with food slightly reduces the rate, but not the extent of absorption. INDICATIONS AND CLINICAL USE

SABRIL (vigabatrin) is indicated for the adjunctive management of epilepsy which is not satisfactorily controlled by conventional therapy. There is insufficient data on the usefulness of vigabatrin in monotherapy at this time.

Vigabatrin should be used under close monitoring by a neurologist. CONTRAINDICATIONS

SABRIL (vigabatrin) is contraindicated in pregnancy and lactation (see WARNINGS) and in patients with a known hypersensitivity to vigabatrin or to any components of the product.

\section{WARNINGS}

\section{Neurotoxicity in Anlmals}

Rat, Mouse and Dog: Safety studies carried out in the rat, mouse and dog at doses of 30 to $50 \mathrm{mg} / \mathrm{kg} / \mathrm{day}$ and higher, caused doseand time-dependent micro-vacuotation within certain white matter tracts of the brain (the cerebellum, reticular formation and thalamus in rodents and the columns of the fornix and optic tracts in dogs were most affected). The microvacuolation was caused by the separation of the outer lamellar sheath of myelinated fibres, a change characteristic of non-inflammatory intramyelinic edema.

In both the rat and dog (mouse was not tested), the intramyelinic edema was reversible after stopping the administration of vigabatrin: however, in the mouse and rat, residual changes consisting of swollen axons and mineralised microbodies were observed.

Monkey: In monkeys, the oral administration of $300 \mathrm{mg} / \mathrm{kg} / \mathrm{day}$ for 16 months produced minimal microvacuolation with equivoca differences between treated and control animals. Low oral absorption of vigabatrin in the monkey resulted in an actual absorbed dose of $75 \mathrm{mg} / \mathrm{kg} /$ day. In spite of the poor absorption, cerebrospinal fluid (CSF) levels of vigabatrin in the monkeys were comparable to those seen in rats treated with $300 \mathrm{mg} / \mathrm{kg} / \mathrm{day}$; however, GABA levels in the CSF and the brain cortex in treated monkeys were not significantly different from untreated monkeys. This finding may explain the reason for the equivocal effects, since the intramyelinic edema associated with vigabatrin treatment appears to be related to increased brain GABA levels.

Evoked Potentials

Evoked polentials in animals: In the dog, studies indicate that intramyelinic edema is associated with increased latencies in somatosensory and visual evoked potentials. Magnetic resonance imaging (MRI) changes also correlated with intramyelinic edema in the fornix, thalamus and hypothalamus.

Evoked potentlals in man: No increased evoked potentia latencies have been observed in man. Two hundred and twenty-one patients treated for 4.5 months showed no significant evoked potential latency changes at the end of treatment as compared to
Seline. MRI results in man did not show the changes observed in

Postmortem neuropathological changes seen in 11 patients who were treated with vigabatrin (mean duration of treatment was 28 months, and the longest treatment was 6 years) showed no myelin vacuolation in the white matter that was considered to be outside of the control range.

Although clinical trials have not revealed the type of neurotoxicity seen in animal studies, because of increased CSF GABA levels observed in humans, it is recommended that patients treated with vigabatrin be closely observed for adverse effects on neurological function, with special attention to visual disturbance.

Use in Pregnancy and Lactation In a teratology study in the rabbit a dose-related incidence, $2 \%$ and $9 \%$, of cleft palate was observed at doses of 150 and $200 \mathrm{mg} / \mathrm{kg} /$ day, respectively.

In animal reproductive studies neurohistopathology was not performed on the fetuses, therefore it is not known whether microvacuolation occurred in utero. The possibility that microvacuolation of other neurotoxicity may occur in human fetuses cannot be discarded.

\section{PRECAUTIONS}

Use in Patients with a History of Psychosis Behavioural disturbances such as aggression and psychotic episodes have been reported following initiation of vigabatrin therapy. A history of abnormal behaviour or psychosis appears to be a predisposing factor for such reactions, therefore treatment in such patients should be initiated cautiously at low doses and with frequent monitoring.

Use in the Elderly and in Patients with Renal Impairment Vigabatrin is eliminated via the kidney and caution should be exercised when administering the drug to elderly patients and to patients with renal impairment (see DOSAGE AND ADMINISTRATION).

Use in Patients with Myocionic Seizures As with other antiepileptic orugs, some patients may experience an increase in seizure frequency with vigabatrin. Patients with myoclonic seizures may be particularly liable to this effect.

Discontinuation of Therapy As with other antiepileptic orugs, abrupt discontinuation may lead to rebound seizures. If a patient is to be withdrawn from vigabatrin treatment, it is recommended that this be done gradually by reducing the dose over a 2 to 4 week period if possible.

Drug Interactions A gradual reduction of about $20 \%$ in plasma phenytoin concentration has been observed following add-on therapy with vigabatrin. The mechanism whereby this occurs is unknown. Limited data from clinical trials suggest that increasing the phenytoin dose to compensate may not be necessary.

Occupational Hazards Patients with uncontrolled epilepsy should not drive or handle potentially dangerous machinery. During clinical trials, the most common adverse reactions observed were drowsiness and fatigue. Patients should be advised to refrain from activities requiring mental alertness or physical coordination until they are sure that vigabatrin does not affect them adversely.

ADVERSE REACTIONS

SABRIL (vigabatrin) is generally well tolerated in epileptic patients. Adverse events are mainly CNS-related and probably a secondary consequence of increased GABA levels caused by vigabatrin. The safety of vigabatrin was evaluated in 2081 epileptic patients treated in clinical trials. The relationship of adverse events to vigabatrin therapy was not clearly established as patients were taking other antiepileptic drugs concomitantly. The most trequently reported adverse events were somnolence $(12.5 \%)$, tatigue $(9.2 \%)$, and weight gain $(5.0 \%)$.

The following adverse events were observed in more than $1 \%$ of patients:

\begin{tabular}{|l|c|c|}
\hline \multicolumn{3}{|c|}{ Adverse Events Reported } \\
By More Than 1\% of Patients \\
\hline $\begin{array}{l}\text { Body System/ } \\
\text { Adverse Event }\end{array}$ & $\begin{array}{c}\text { Number of } \\
\text { Patients }\end{array}$ & $\begin{array}{c}\text { Incidence } \\
\text { n=2081 }\end{array}$ \\
\hline Nervous & & \\
somnolence & 261 & 12.5 \\
headache & 80 & 3.8 \\
dizziness & 79 & 3.8 \\
nervousness & 56 & 2.7 \\
depression & 52 & 2.5 \\
memory disturbances & 47 & 2.3 \\
diplopia & 46 & 2.2 \\
aggression & 42 & 2.0 \\
ataxia & 39 & 1.9 \\
vertigo & 39 & 1.9 \\
hyperactivity & 37 & 1.8 \\
vision abnormal & 34 & 1.6 \\
confusion & 29 & 1.4 \\
insomnia & 26 & 1.3 \\
impaired concentration & 25 & 1.2 \\
personality disorder & 23 & 1.1 \\
agitation & 21 & 1.0 \\
\hline Digestive & & \\
abdominal pain & 34 & 1.6 \\
constipation & 29 & 1.4 \\
vomiting & 28 & 1.4 \\
nausea & 28 & 1.4 \\
\hline Body as a Whole & & \\
fatigue & 192 & 9.2 \\
weight gain & 104 & 5.0 \\
asthenia & 23 & 1.1 \\
\hline
\end{tabular}

Adverse events reported with a frequency of less than $1 \%$ include: anxAdy emotional lability, behavioural disturbances including psychosis, irritability, tremor, abnormal gait, speech disorder, increased appetite, and dyspepsia.

As with other antiepileptic drugs, some patients may experience an increase in seizure frequency with vigabatrin treatment (see PRECAUTIONS)

Laboratory data indicate that vigabatrin treatment does not lead to renal or hepatic toxicity. Chronic treatment with vigabatrin may be associated with a slight decrease in hemoglobin, which rarely attains clinical significance.

Pediatric Safety Safety data is available in 299 children, aged 2 months to 16 years ( 1 patient was 18 years of age), participating in clinical trials with vigabatrin. Relationship of adverse events to vigabatrin therapy was not clearly established as children were taking other antiepileptic drugs concomitantly.

The most frequent adverse event observed in children was "hyperactivity" (reported as hyperkinesia $7.7 \%$, agitation $2.3 \%$, excitation $0.3 \%$ or restlessness $0.7 \%$ ), which was observed in $11.0 \%$ of children, an incidence higher than that seen in adults. Other commonly reported adverse events were somnolence $(8.0 \%)$ and weight gain $(3.0 \%)$.

The following adverse events were reported in children with a frequency greater than $1 \%$ :

\begin{tabular}{|l|c|c|}
\hline \multicolumn{3}{|c|}{$\begin{array}{c}\text { Adverse Events Reported By More Than 1\% } \\
\text { of Pediatric Patients }\end{array}$} \\
\hline $\begin{array}{l}\text { Body System/ } \\
\text { Adverse Event }\end{array}$ & $\begin{array}{c}\text { Number of } \\
\text { Patients }\end{array}$ & $\begin{array}{c}\text { Incidence } \\
\text { n=299 }\end{array}$ \\
\hline Nervous & & \\
somnolence & 24 & 8.0 \\
hyperkinesia & 23 & 7.7 \\
aggression & 8 & 2.7 \\
insomnia & 8 & 2.7 \\
agitation & 7 & 2.3 \\
ataxia & 7 & 2.3 \\
emotional lability & 3 & 1.0 \\
headache & 3 & 1.0 \\
increased seizures & 3 & 1.0 \\
\hline Digeslive & & \\
vomiting & 6 & 2.0 \\
nausea & 3 & 1.0 \\
increased saliva & 3 & 1.0 \\
\hline Body as a Whole & & 3.0 \\
weight gain & 9 & 2.7 \\
fatigue & & 1.0 \\
hypotonia & 3 & \\
\hline
\end{tabular}

SYMPTOMS AND TREATMENT OF OVERDOSAGE

There is no specific antidote. The usual supportive measures should be employed.

Two cases of SABRIL (vigabatrin) overdose have been reported. In the first case, the patient accidentally took a dose of $14 \mathrm{~g}$ daily for 3 days and transient vertigo and tremor were reported. In the second case, an 18-year old female took $30 \mathrm{~g}$ of vigabatrin and $250 \mathrm{mg}$ of chlorazepate in a suicide attempt. The patient was admitted to hospital in a state of coma which lasted four days; however, the coma was considered to be due to the chlorazepate rather than vigabatrin. The patient recovered without sequelae.

DOSAGE AND ADMINISTRATION

SABRIL (vigabatrin) is intended for oral administration once or wice daily and may be taken with or without food. Sabril should be added to the patient's current antiepileptic therapy.

Instructions to the patient on the use of SABRIL are provided in the INFORMATION FOR THE CONSUMER section.

Adults The recommended starting dose is $1 \mathrm{~g}$ /day, although patients with severe seizure manifestations may require a stanting dose of up to $2 \mathrm{~g} /$ day. The daily dose may be increased or decreased in increments of $0.5 \mathrm{~g}$ depending on clinical response and tolerability. The optimal dose range is between 2-4 g/day. Increasing the dose beyond $4 \mathrm{~g} /$ day does not usually result in improved efficacy and may increase the occurrence of adverse reactions.

Children The recommended starting dose in children is $40 \mathrm{mg} / \mathrm{kg} / \mathrm{day}$, increasing to $80-100 \mathrm{mg} / \mathrm{kg} / \mathrm{day}$ depending on response. Therapy may be started at $0.5 \mathrm{~g} / \mathrm{day}$, and raised by increments of $0.5 \mathrm{~g} / \mathrm{day}$ weekly depending on clinical response and tolerability.

\begin{tabular}{|r|c|c|}
\hline Bodywaight & Daily Oose & No. Tablets/Day \\
\hline $10-15 \mathrm{~kg}$ & $0.5-1 \mathrm{~g} /$ day & $1-2$ tablets/day \\
$16-30 \mathrm{~kg}$ & $1-1.5 \mathrm{~g} /$ day & $2-3$ tablets/day \\
$31-50 \mathrm{~kg}$ & $1.5-3 \mathrm{~g} /$ day & $3-6$ tablets/day \\
$>50 \mathrm{~kg}$ & $2-4 \mathrm{~g} /$ day & $4-8$ tablets/day \\
\hline
\end{tabular}

Elderly and Renally Impaired Patients Vigabatrin is almost exclusively eliminated via the kidney and, therefore, caution should be exercised when administering the drug to the elderly, and more particularly to patients with creatinine clearance less than 60 $\mathrm{mL} / \mathrm{min}$. It is recommended that such patients be started on a lower dose of vigabatrin and observed closely for adverse events such as sedation and confusion. 
Tablets Each SABRIL (vigabatrin) $500 \mathrm{mg}$ tablet is white to offwhite film-coated, oval biconvex, and imprinted "SABRIL" on one side. SABRIL is available in HDPE bottles containing 100 tablets.

Product Monograph available upon request.

Reterences:

1. Drugs Reprint. Adis International: June 1991, Vol. 41 No. 6 , pg. 892.

2. Riekkinen et al. Cerebrospinal fluid GABA and seizure control with vigabatrin. Br. J. Clin. Pharmac. (1989).27-87S-94S.

3. Reynolds, EH et al. A controlled trial of gamma-vinyl-GABA (vigabatrin) in drug-resistant epilepsy. Br. J. of Clin. Pract. Suppl. 61

4. Remy C. \& Beaumont D. Efficacy and safety of vigabatrin in the long-term treatment of refractory epilepsy. Br. J. Clin. Pharmac. (1989).27.125S-129S

5. Browne, TR, Mattson, RH et al. Vigabatrin for refractory complex partial seizures: Multicenter single-blind study with long-term follow-up. Neurology 1987: 37: 184-189.

6. The Belgian Vigabatrin Evaluation Group' and A. Lhoir*: Vigabatrin in uncontrolled seizures: Belgian clinical experience. Clinical Neurotogy and Neurosurgery. 96 (1994) 42-46.

7. Data on file, Marion Merrell Dow Canada 1994.

8. Product Monograph. Marion Merrell Dow Canada, 1994.

9. Livingston, JH, Beaumont $\mathrm{D}$. et al. Vigabatrin in the treatment of epilepsy in children. Br.J Clin Pharmac (1989) 27.109S-112S

10. Oijkstra, JB, MCGuire, AM, \& Trimble, MR. The effect of vigabatrin on cognitive function and mood. Human Psychopharmacology, vol. 7,000-000 01992

11. Dodrill, CB, Arnett, JL et al. Evaluation of the effects of vigabatrin on cognitive abilities and quality of life in epilepsy. Neurology 1993:250|-2507.

12. McGuire, AM Duncan, JS, Trimble, MR. Effects of vigabatrin on cognitive function and mood when used as add-on therapy in patients with intractable epilepsy. Epilepsia. 33(1):128-134 1992.

13. Schecter, PJ, Hanke, NFJ et al. Biochemical and clinica effects of $y$-vinyl GABA in patients with epilepsy. Neurology $34: 182-86(1984)$.

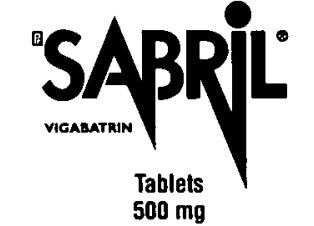

Antiepileptic

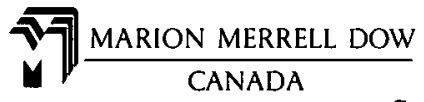

Laval, Quebec H7L 4A8 See pages vi, vii.

SABR94-020E

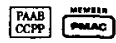

\section{ADVERTISERS INDEX}
Abbott
Epival - xvii, xviii
Ciba/Geigy
Tegretol - obc, xv, xxiv, xxv
Draxis
Permax - v, xxviii
Dupont
Sinemet - xii, xxi, xxii
Frank Horner - ix, xi
Hoescht
Frisium - ibc, iii, xxii
Marion Merrell Dow
Sabril - vi, vii, xxvi, xxvii
Parke Davis
Neurontin - xiii, $\mathrm{xix}, \mathrm{xx}$
Sandoz Canada
Organ Donation - $\mathrm{x}$
Parlodel - ifc, iv
Classified Ads
$-x x v i i, x x v i i i, x x i x$

\section{Movement Disorder Neurologist}

Movement Disorders Neurologist sought at The Toronto Hospital. Training and research ability in Movement Disorders required. The successful candidate will be expected to develop his/her own research interests, as well as participating in clinical and research aspects of the Movement Disorders Program. Academic appointment in the Division of Neurology, University of Toronto, and salary will be commensurate with training and experience.

In accordance with its employment equity policy, the University of Toronto encourages applications of qualified women and men, members of visible minorities, aboriginal people and persons with disabilities. In accordance with Canadian Immigration requirements this advertisement is directed to Canadian citizens and permanent residents. Applicants should be eligible for certification in Neurology by the Royal College of Physicians and Surgeons of Canada.

Please send CV and letter of application to:

$$
\begin{gathered}
\text { Dr. James A. Sharpe } \\
\text { Professor and Head of Neurology } \\
\text { University of Toronto } \\
\text { The Toronto Hospital } \\
\text { 399 Bathurst Street } \\
\text { Toronto, Ontario, Canada } \\
\text { M5T 2S8 }
\end{gathered}
$$

Closing date for applications is October 14, 1994

\section{Private Practice Child Neurology Opportunity}

Busy child neurologist in Upstate New York would like to provide more timely service to the pediatric community. One or two colleagues, U.S. BC/BE with comfort/experience in electroencephalography would be most desirable. The practice is limited to $100 \%$ child and adolescent neurology.

A private practice setting offers flexibility with ties with two teaching hospitals affiliated with a major pediatric training program and a third hospital with a family practice teaching program. Precise terms are negotiable depending on needs and experience, with the prospect of eventual partnership anticipated.

Syracuse, a mid sized metropolitan community, and its suburbs provide excellent public and private school options. Real estate is affordable. A major University provides several excellent athletic teams, as well as additional cultural and educational opportunities. The city provides numerous cultural and entertainment out-lets. This beautiful Central New York community is a pleasant 4 hour drive to Niagara Falls, a 4 to 5 hour drive to Toronto or Montreal, and a 5 to 6 hour drive to New York City.

Please send inquiries and C.V. to:

Dr. Nancy Havernick

5850 Heritage Landing Dr.,

E. Syracuse, N.Y. 13057

or call (315) 446-2985 during week-day business hours. 


\section{PPERMAX' \\ pergolide 'mesylate}

PERMAX : Pergolide Mesylate tablets THERAPEUTIC CLASSIFICATION: Dopamine Agonist PRESENTATION: Tablets containing $.05 \mathrm{mg}$ or .25 $\mathrm{mg}$ or $1 \mathrm{mg}$ of pergolide base.

INDICATIONS AND CLINICAL USE: As an adjunctive treatment to levodopa in the management of the signs and symptoms of Parkinson's disease.

CONTRAINDICATIONS: Hypersensitivity to this drug or other ergot derivatives.

WARNINGS: Patients should be warned to begin therapy with low doses and to increase dosage in carefully adjusted increments over a period of 3 to 4 weeks, to minimize the risk of syncope, symptomatic postural and /or sustained hypotension. In controlled trials, pergolide mesylate with L-dopa caused hallucinosis in about 14 per cent of patients, as opposed to 3 per cent taking placebo with L-dopa. Caution should be exercised when administering to patients prone to cardiac dysrhythmias or with significant underlying cardiac disease. In a placebocontrolled study, patients taking pergolide mesylate had significantly more episodes of atrial premature contractions (APC's) and sinus tachycardia. Care should be exercised when administering Permax concomitantly with antihypertensive agents or other medications known to lower blood pressure. Patients should be cautioned with regard to engaging in activities requiring rapid and precise responses, such as driving an automobile or operating machinery.

PRECAUTIONS: Abrupt discontinuation of pergolide mesylate, in patients receiving it chronically as an adjunct to L-dopa, may precipitate the onset of hallucinations and confusion. Administration to patients receiving L-dopa may cause and/or exacerbate pre-existing dyskinesias. Patients and their families should be informed of the common adverse consequences of the use of pergolide mesylate and the risk of hypotension. Patients should be advised to tell their doctors if they become pregnant, intend to become pregnant, or if they are breast feeding. Drug interactions: Dopamine antagonists, such as the neuroleptics (phenothiazines, butyrophenones, thioxanthines) or metoclopramide, ordinarily should not be administered concurrently with pergolide mesylate (a dopamine agonist); these agents may diminish the effectiveness of pergolide mesylate. Caution should be exercised if pergolide is co-administered with anti-hypertensive agents. Pregnancy: In animal studies there was no evidence of harm to the fetus due to pergolide mesylate. There are, however, no adequate and well-controlled studies in pregnant women. This drug should be used during pregnancy only if the benefits outweigh the potential risk to the fetus. Nursing mothers: It is not known whether pergolide is excreted in human milk. The pharmacological action of pergolide mesylate suggests it may interfere with lactation. A decision should be made whether to discontinue nursing or the drug, taking into account the importance of the drug to the mother

ADVERSE REACTIONS: Body as a whole: Pain, abdominal pain, injury, accident, headache, asthenia, chest pain, back pain, fever, flu syndrome, neck pain. Gastrointestinal: Nausea, constipation, diarrhea, dyspepsia, anorexia, dry mouth, dysphagia. Special senses: Diplopia, abnormal vision, taste perversion eye disorder. Other events that have been reported include hypotension, atrial premature contractions and sinus tachycardia. Nervous system:

Hallucinations, psychosis, paranoid reaction, personality disorder, akinesia, dyskinesia, choreoathetosis, dystonia, tremor, abnormal gait, incoordination, speech disorders, dizziness, confusion, depression, anxiety, somnolence, insomnia, abnormal dreams, amnesia. Respiratory system: Rhinitis, dyspnea, pneumonia, pharyngitis, cough increased. Metabolic and nutritional findings: Peripheral edema, weight loss, weight gain. Musculoskeletal system: Twitching, myalgia, arthralgia. Skin and appendages system: Sweating, rash. Urogenital system: Urinary tract infection, urinary frequency, urinary incontinence, prostatic disorder, dysmenorrhea, hematuria. Hemic and lymphatic system: Anemia.

OVERDOSAGE: There is no clinical experience with massive overdosage. Symptoms and signs have included vomiting, hypotension, agitation, severe hallucinations, severe involuntary movements, tingling sensations, palpitations and ventricular extrasystoles. Treatment: Symptomatic supportive therapy is recommended to maintain arterial blood pressure. Cardiac function should be monitored; an antiarrhythmic agent may be necessary. If signs of CNS stimulation are present a phenothiazine, or other butyrophenone neuroleptic agent, may be indicated. DOSAGE AND ADMINISTRATION: Pergolide is administered orally. Administration should be initiated with a daily dosage of $0.05 \mathrm{mg}$ for the first two days. The dosage should then be gradually increased by 0.1 or $0.15 \mathrm{mg} /$ day every third day over the next 12 days of therapy. The dosage may then be increased by $0.15 \mathrm{mg} /$ day every third day until an optimal therapeutic dosage is achieved. Pergolide mesylate is usually administered in divided doses 3 times per day. During dosage titration, the dosage of concurrent L-dopa may be cautiously decreased.

The product monograph is available upon request.

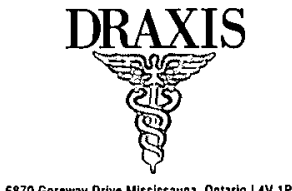

See page $v$.

\section{Neurosurgical Fellowships July 1995 - June 1996}

THE DIVISION OF NEUROSURGERY, THE TORONTO HOSPITAL, UNIVERSITY OF TORONTO is offering subspecialty fellowships in Neurosurgery. The Division of Neurosurgery at the hospital comprises 10 full time neurosurgeons, performs over 1,700 procedures per year and has a large postgraduate training program in neurosurgery. The Toronto Hospital Division of Neurosurgery offers subspecialty fellowships in the following areas of neurosurgery:

Spinal, functional/stereotactic, neuro-oncology, cerebrovascular, and skull base surgery.

The positions are funded. Applicants must have completed their neurosurgical training and be eligible for licensure in the Province of Ontario (Medical Council of Canada Qualifying Examination or accepted equivalent, English Proficiency Examinations where applicable). Interested applicants should include their curriculum vitae and a description of their reasons for selecting a specific subspecialty fellowship.

Address correspondence to:

Dr. M. Christopher Wallace, Director

Fellowships Program

The Toronto Hospital - Western Division

399 Bathurst St.

2-427 McLaughlin Wing

Toronto, Ontario, Canada

M5T 2S8

Application Deadline: November 1, 1994

\section{Director, Centre for Research in Neurodegenerative Diseases Faculty of Medicine, University of Toronto}

The Faculty of Medicine at the University of Toronto is seeking a Director of its Centre for Research in Neurodegenerative Diseases. The Centre has nine independent investigators currently carrying out basic and clinical research related to Alzheimer's and other neurodegenerative diseases. The Centre occupies 15,000 square feet of newly renovated laboratory and office space.

The Director is responsible for the operations of the Centre including the recruitment of investigators. Candidates should have an active basic or clinical research program, relevant to neurodegenerative diseases, a strong record of scholarly achievement, leadership qualities and administrative skills. The successful applicant will be given a full-time academic appointment, as Associate Professor or Professor, in an appropriate department of the Faculty of Medicine.

Applications should be sent to:

$$
\begin{aligned}
& \text { Dr. Arnie Aberman } \\
& \text { Dean, Faculty of Medicine } \\
& \text { University of Toronto } \\
& \text { Room } 2109 \\
& \text { Medical Sciences Building } \\
& 1 \text { King's College Circle } \\
& \text { Toronto, Ontario M5S 1A8 } \\
& \text { Fax (416) 978-1774 }
\end{aligned}
$$

Applicants should enclose a current curriculum vitae.

The University of Toronto encourages applications from qualified men and women, members of visible minorities, aboriginal peoples and persons with disabilities. In accordance with Canadian Immigration requirements, this advertisement is directed to Canadian citizens and permanent residents.

Closing date for applications is October 14, 1994. 


\section{FELLOWSHIP IN MOVEMENT DISORDERS}

A Clinical Fellowship in Movement Disorders is available at The University of Calgary and Foothills Hospital starting July 1,1995 . The candidate will be expected to participate actively in clinical research and patient management. $\mathrm{He} / \mathrm{she}$ must have completed a Neurology Training Program.

For further information contact:

Dr. O. Suchowersky

Director, Movement Disorders Clinic

UCMC, Area 3, 3350 Hospital Dr. N.W.

Calgary, Alberta

T2N 4N1

Ph: (403) 670-4364

Fax: (403) 283-2907
The University of Manitoba

Department of Surgery

\section{HEAD, SECTION OF NEUROSURGERY}

The Department of Surgery, Faculty of Medicine, University of Manitoba is searching for a contingent geographical full-time Head of the Section of Neurosurgery effective JANUARY 1, 1995. The responsibilities include the coordination of clinical services between two major teaching Hospitals, the Health Sciences Centre and the St. Boniface General Hospital as well as recruitment, organization, and supervision of undergraduate medical education and postgraduate training. The incumbent shall foster research initiatives and candidates should have an established reputation of clinical experience and research accomplishments.

Candidates must have Senior Specialty qualifications in Neurosurgery in the country of current practice and must be eligible for registration with the College of Physicians and Surgeons of Manitoba. Eligibility for, or certification in, Neurosurgery by the Royal College of Physicians and Surgeons of Canada is required.

Specific requirements include the following: substantial record of academic achievement in Neurosurgery with extensive experience in teaching and research; proven administrative experience in an academic environment; demonstrated constructive skills in interpersonal relations and communication. Remuneration and academic rank will be commensurate with experience and qualifications.

The University of Manitoba encourages applications from qualified women and men, including members of visible minorities, Aboriginal people, and persons with disabilities. The University offers a smoke-free environment, save for specially designated areas. In accordance with Canadian Immigration requirements, this advertisement is directed to Canadian citizens and permanent residents.

Interested candidates should apply, enclosing a curriculum vitae in writing to:

$$
\text { Dr. R.J.W. Blanchard }
$$

Professor and Head, Department of Surgery

Health Sciences Centre

GC411-820 Sherbrook Street

Winnipeg, Manitoba

R3A 1 R9

Closing date for receipt of applications is AUGUST 31, 1994.

\section{NEUROSURGEON \\ Pasadena, California}

Two active neurosurgeons in established private practice with privileges at Huntington Memorial Hospital in Pasadena and teaching affiliation with USC, invite applications for a third associate to join practice leading to partnership opportunity. Position open for qualified candidate who is eligible for U.S. registration. Excellent starting salary with incentive benefits guaranteed. Immigration arrangements provided and confidentiality ensured. Call or write for further information or fax C.V. to:

\section{PACIFIC RIM HEALTH ADMINISTRATION}

530 - 3rd Street

New Westminster, BC V3L 2S8

Tel/Fax: (604) 526-1314

\section{NeURology RESIDENCY MCGILl UNIVERSITY QUEBEC}

Positions for July 1, 1995 for training in neurology and the neurosciences leading to FRCP certification. Applicants must be Canadian graduates, currently residing outside Quebec, who have done either two years of training in internal medicine, one year of medicine and an internship year, or two years of pediatrics. The core threeyear program consists of 27 months of clinical training (adult and child neurology, epilepsy/ EEG, neuromuscular disease/EMG), a six-month research rotation and a three-month elective. The emphasis is on contemporary basic neuroscience and excellent clinical training. Apply to:

\author{
Dr. Gordon S. Francis, Director \\ Neurology Residency Program \\ Montreal Neurological Institute \\ 3801 University Street \\ Montreal, Quebec \\ H3A 2B4
}

Telephone (514) 398-1904 


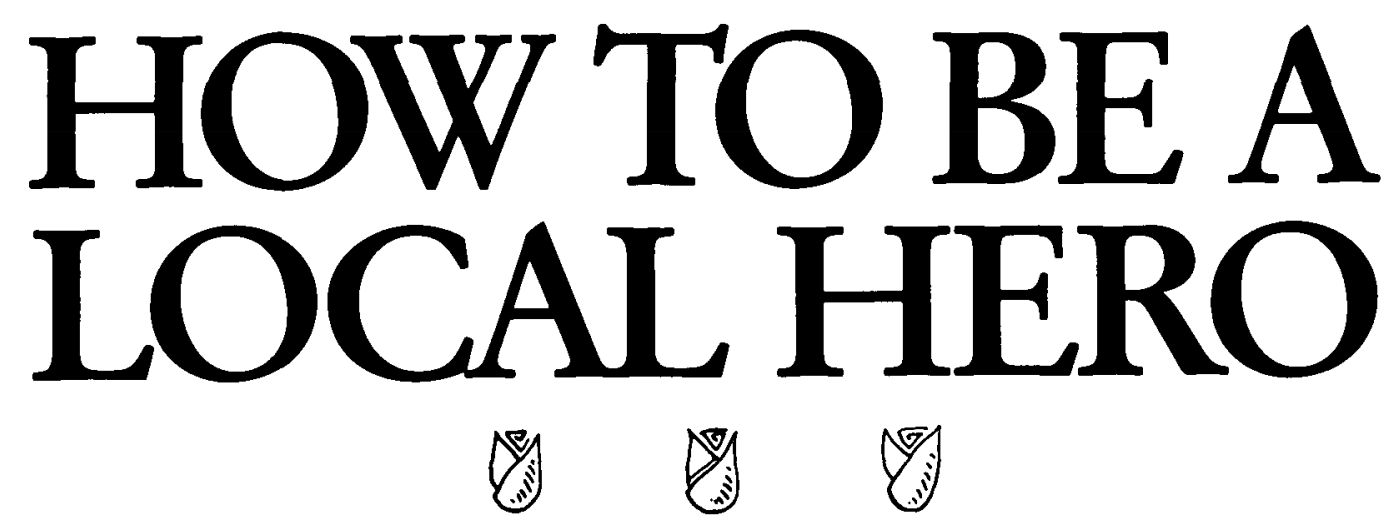

BE PT You'd like to help every one, but it's just not possible. Local Heroes know that the answer is to be picky. Review the causes you already support and be sure that your experience with each of them is rewarding. $\approx$ Then think about other issues you feel are critical to you and your community. Now look for the organizations that work in these areas. Call them up, visit their offices, or write for their brochures and find out

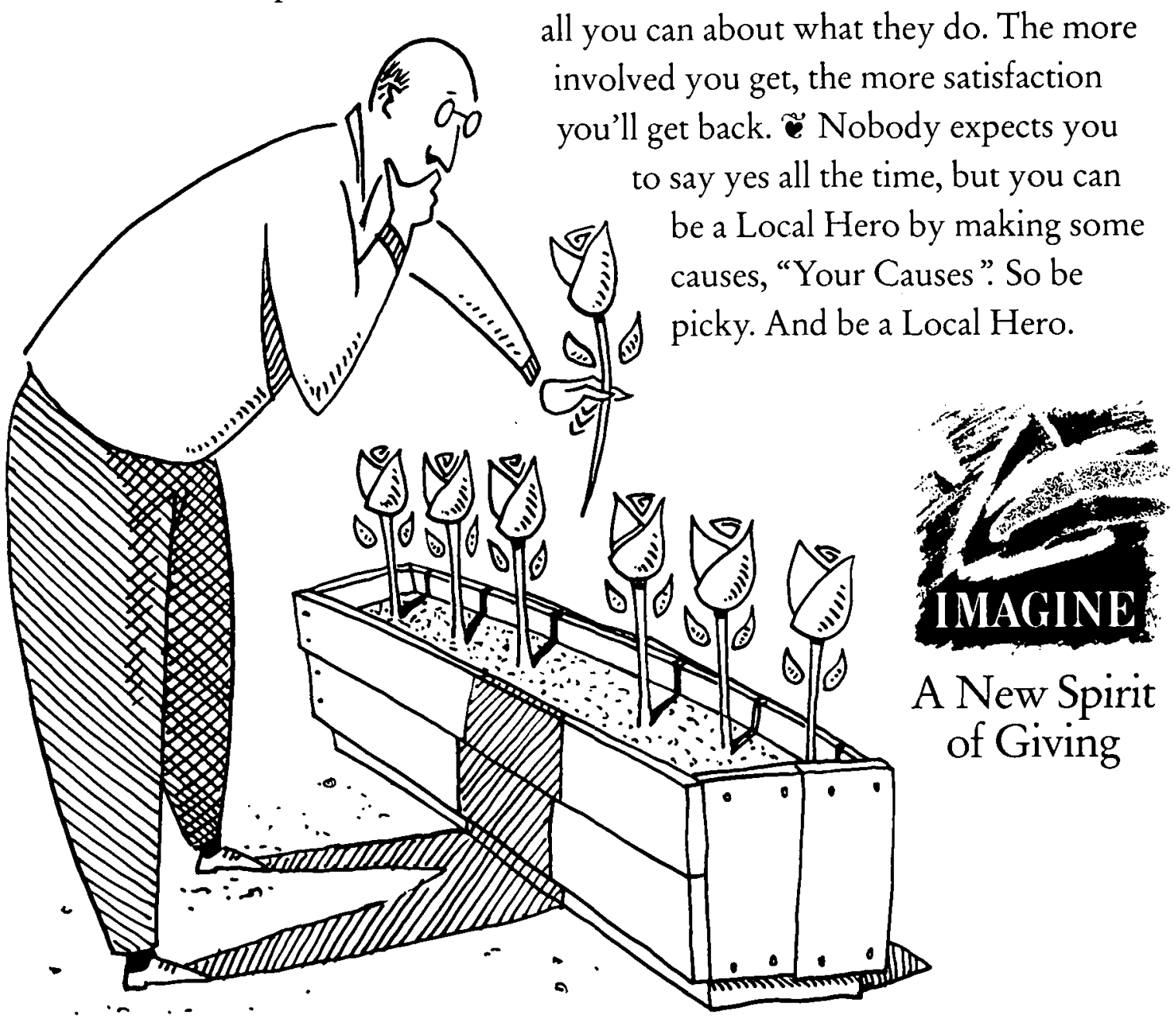

A national program to encourage giving and volunteering. 


\section{A well}

orchestrated

\section{approach}
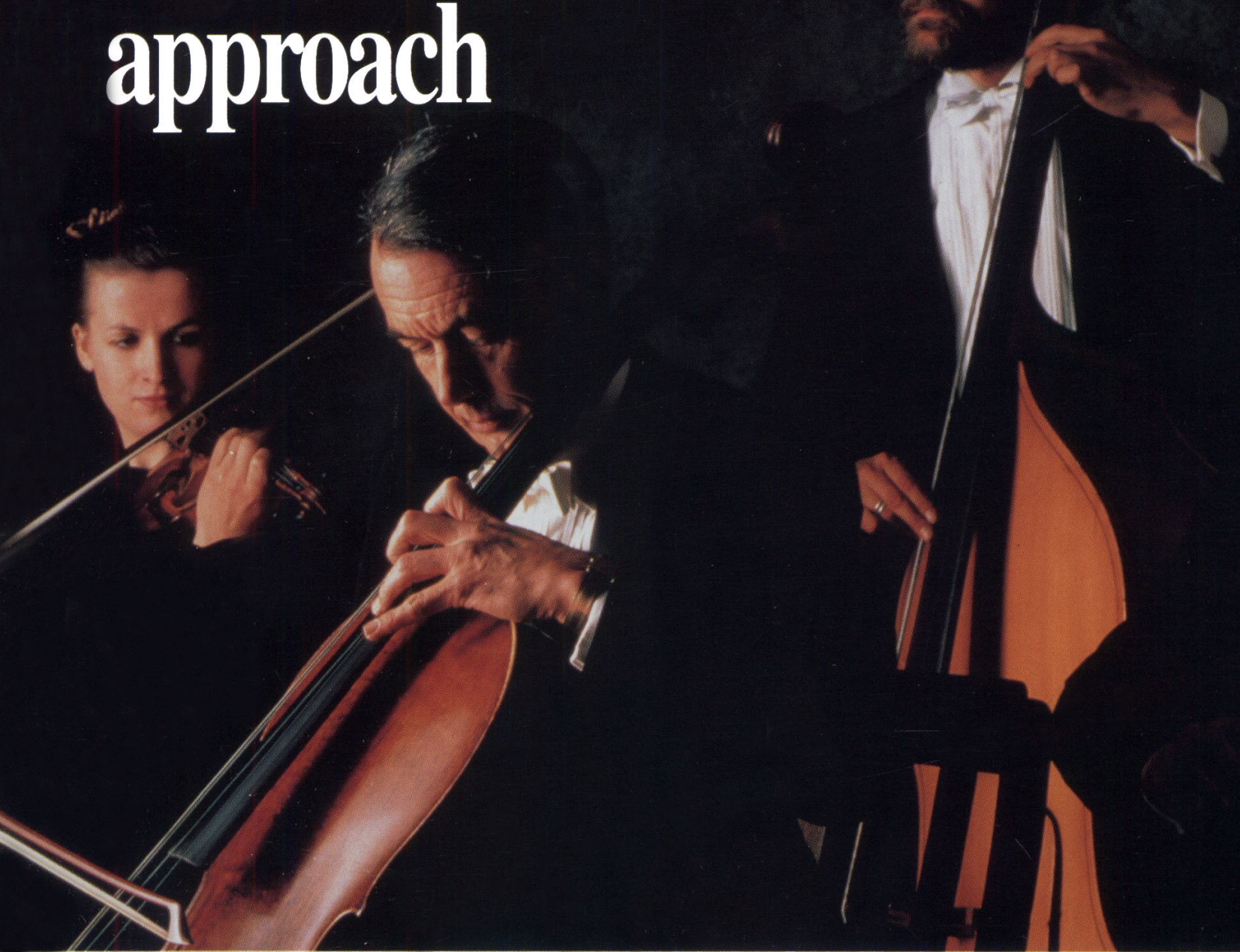

Rational therapy with Frisium is a well orchestrated approach to complete seizure control in patients of all ages, regardless of seizure type. Adverse events with Frisium are generally mild and transient.' Clinically significant drug interactions are uncommon, and impairment of alertness is less pronounced with Frisium than with other benzodiazepines.

Help keep these patients in harmony with their surroundings.

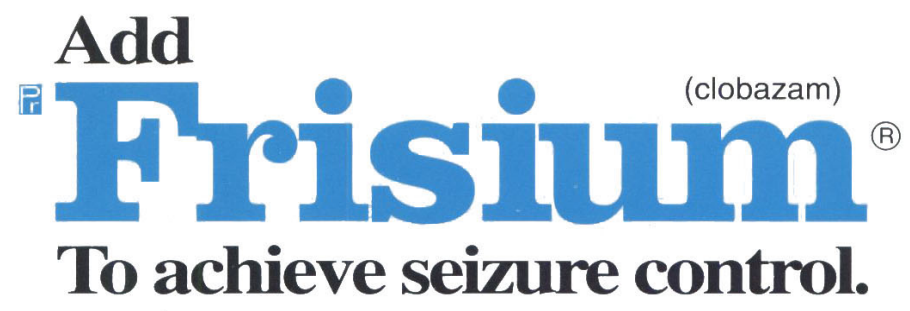




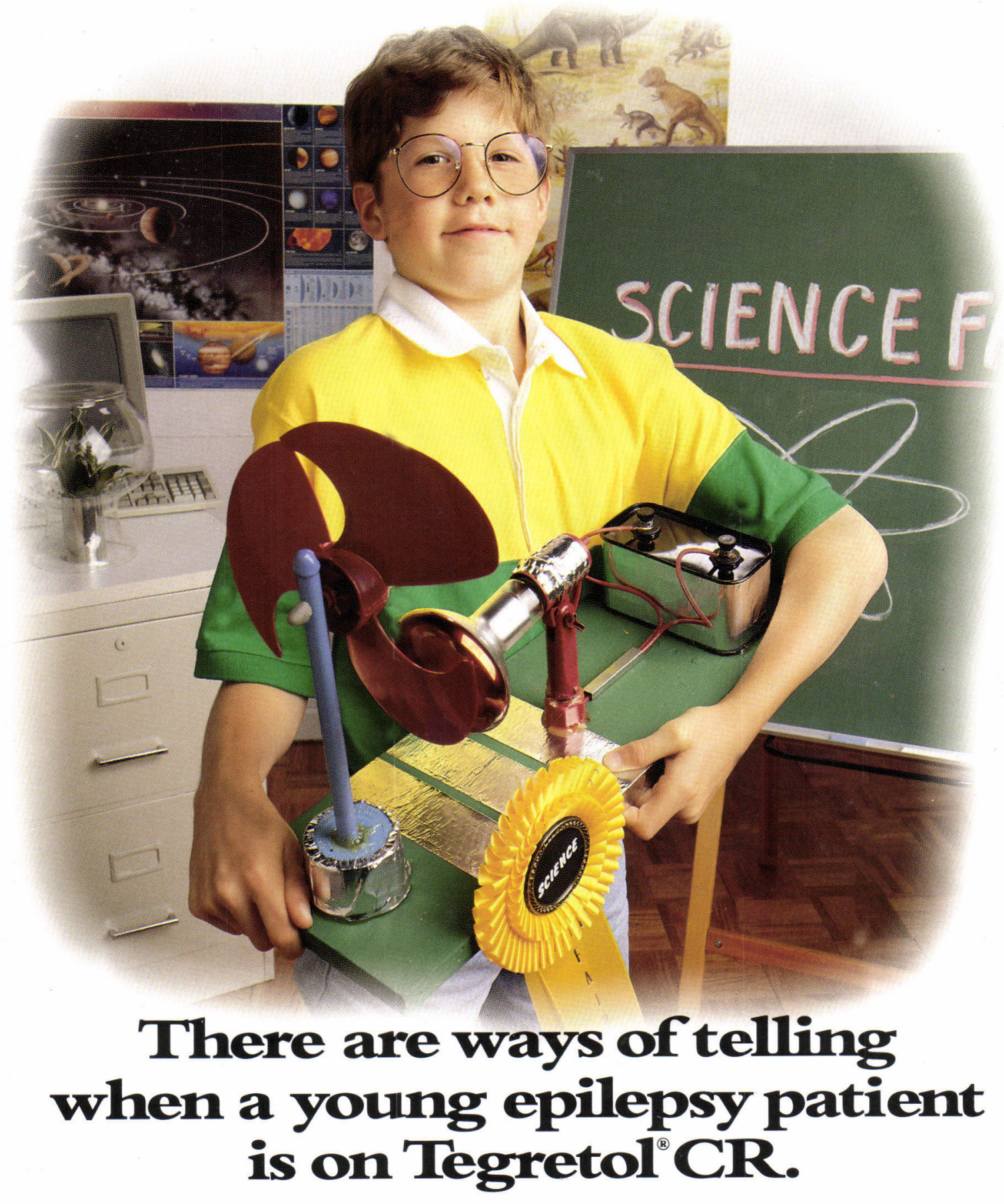

\section{Excellent Seizure Control.}

[Tegreto $1^{\circledR}$ CR (controlled-release carbamazepine) controls seizures in many patients-with little impact on cognitive function.2 Tegretol CR can leave many patients free to think clearly and do their best. ${ }^{1,2}$

\section{Consistent Blood Levels.}

Tegretol CR delivers fewer "peaks and valleys" in blood levels than conventional Tegretol. That means fewer side effects and a more stable pattern of cognitive functioning.,
Convenient B.I.D. Dosing.

When initiating or switching therapy, consider Tegretol CR. It comes in easyto-break $200 \mathrm{mg}$ and $400 \mathrm{mg}$ tablets for dosage flexibility, and offers B.I.D. dosing to enhance patient compliance.

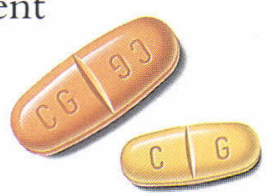

\section{TEGRETOL CR.}

Helping epilepsy patients reach their full potential. 